\title{
Modeling Transport and Flow Regulatory Mechanisms of the Kidney
}

\author{
Anita T. Layton \\ Department of Mathematics, Duke University, P.O. Box 90320, Durham, NC 27708-0320, USA \\ Correspondence should be addressed to Anita T. Layton, alayton@math.duke.edu
}

Received 17 May 2012; Accepted 12 July 2012

Academic Editors: M. Brumen and J. R. C. Piqueira

Copyright () 2012 Anita T. Layton. This is an open access article distributed under the Creative Commons Attribution License, which permits unrestricted use, distribution, and reproduction in any medium, provided the original work is properly cited.

The kidney plays an indispensable role in the regulation of whole-organism water balance, electrolyte balance, and acid-base balance, and in the excretion of metabolic wastes and toxins. In this paper, we review representative mathematical models that have been developed to better understand kidney physiology and pathophysiology, including the regulation of glomerular filtration, the regulation of renal blood flow by means of the tubuloglomerular feedback mechanisms and of the myogenic mechanism, the urine concentrating mechanism, and regulation of renal oxygen transport. We discuss how such modeling efforts have significantly expanded our understanding of renal function in both health and disease.

\section{Introduction}

The kidneys are organs that serve a number of essential regulatory roles. Most of us know that our kidneys function as filters, removing metabolic wastes and toxins from the blood and excreting them through the urine. But the kidneys also serve other essential functions. Through various regulatory mechanisms, the kidneys help maintain the body's water balance, electrolyte balance, and acid-base balance. Additionally, the kidneys produce or activate hormones that are involved in erythrogenesis, calcium metabolism, and the regulation of blood pressure and blood flow.

Most mammalian kidneys have three major sections: the cortex, the outer medulla, and the inner medulla. The outer and inner medulla are collectively referred to as the medulla. The outer medulla may be divided into the outer stripe and the inner stripe.

Despite decades of experimental efforts, some aspects of the fundamental kidney functions remain yet to be fully unexplained. For example, the processes by which a concentrated urine is produced by the mammalian kidney (or, more specifically, the production of a substantial concentrating effect in the inner medulla) when the animal is deprived of water remains one of the longest-standing mysteries in traditional physiology. In conjunction with experimental work, mathematical models have helped to test, confirm, refute, or suggest a number of hypotheses related to the urine concentrating mechanism [2].

This paper will describe modeling efforts that have sought to better understand kidney physiology and pathophysiology, including the regulation of glomerular filtration, the regulation of renal blood flow by means of the tubuloglomerular feedback mechanisms and of the myogenic mechanism, the urine concentrating mechanism, and regulation of renal oxygen transport.

\section{How Is Glomerular Filtration Regulated?}

The functional unit of the kidney is the nephron. Each rat kidney (which is the most well-studied mammalian kidney) is populated by about 38,000 nephrons; each human kidney consists of about a million nephrons. Each nephron consists of an initial filtering component called the renal corpuscle and a renal tubule specialized for reabsorption and secretion. The renal corpuscle is the site of formulation of the glomerular filtration and is composed of a glomerulus and the Bowman's capsule. A glomerulus is a tufts of capillaries arising from the afferent arterioles. Some of the water and solutes in the blood supplied by the afferent arteriole are driven by pressure gradient into the space formed by the Bowman's capsule. The remainder of the blood flows into the efferent arteriole. 
The filtration of blood by glomerular capillaries has been the target of a series of modeling efforts, notably by Deen and coworkers [1,4-10]. Despite the tortuosity of the glomerular capillaries, most glomerular filtration models idealize those capillaries as a network of identical, parallel, and rigid cylinders with homogeneous properties. Model equations typically consist of a system of coupled ODEs expressing fluid and solute conservation:

$$
\begin{aligned}
\frac{\partial}{\partial x} Q & =-\frac{S}{L} J_{v}, \\
\frac{\partial}{\partial x}\left(Q C_{k}\right) & =-\frac{S}{L} J_{k}, \\
\frac{\partial}{\partial x}\left(Q C_{\mathrm{pr}}\right) & =0
\end{aligned}
$$

where $Q$ denotes plasma flow rate, $S$ and $L$ denote the surface area and length of the capillary, $J_{v}$ and $J_{k}$ denote the fluid and solute fluxes, $C_{k}$ denotes the plasma concentration of solute $k$, and the subscript pr denotes protein. Boundary conditions are given for $Q, C_{k}$, and $C_{\mathrm{pr}}$ at the afferent end of the capillary. Volume flux is assumed to be driven by hydrostatic and oncotic pressure differences, and fluxes for small solutes (smaller than proteins) are assumed to be both advective and diffusive, through the fenestrated capillary walls. Typical model results are shown in Figure 1.

Deen and collaborators have published a series of models of glomerular filtration [1,4-10]. Early models represent the capillary wall as an isoporous membrane formed of parallel, cylindrical pores of uniform radius [1]. The isoporous model has the advantage of being relatively easy to formulate and to implement. As discussed by Deen et al. [1], this model successfully predicts clearance data in a few cases, such as in normal and nephritic rats. However, isoporous model predictions are incompatible with experimental results in quite a few human diseases, such as diabetic nephropathy and glomerulonephritis. Thus, heterosporous models were developed that assume that the glomerular barrier can be represented by a distribution of pore sizes. The ability of heteroporous models to describe clearance data in nephrotic humans was found to be much improved over isoporous models. In later studies, Deen and collaborators developed new models of glomerular filtration based on the specific ultrastructure of the capillary wall. These models sought to relate the permeability properties of the wall to its unique cellular, and even molecular, characteristics $[7,9,10]$.

\section{How Does the Kidney Regulate Renal Blood Flow?}

Normal renal function requires that the fluid flow through the glomerulus and nephron be kept within a narrow range. When tubular flow rate falls outside of that range, the ability of the nephron to maintain salt and water balance may be compromised. Tubular flow rate depends, in large part, on glomerular filtration rate, which is regulated by several mechanisms, including the tubuloglomerular feedback (TGF) and the myogenic mechanism.

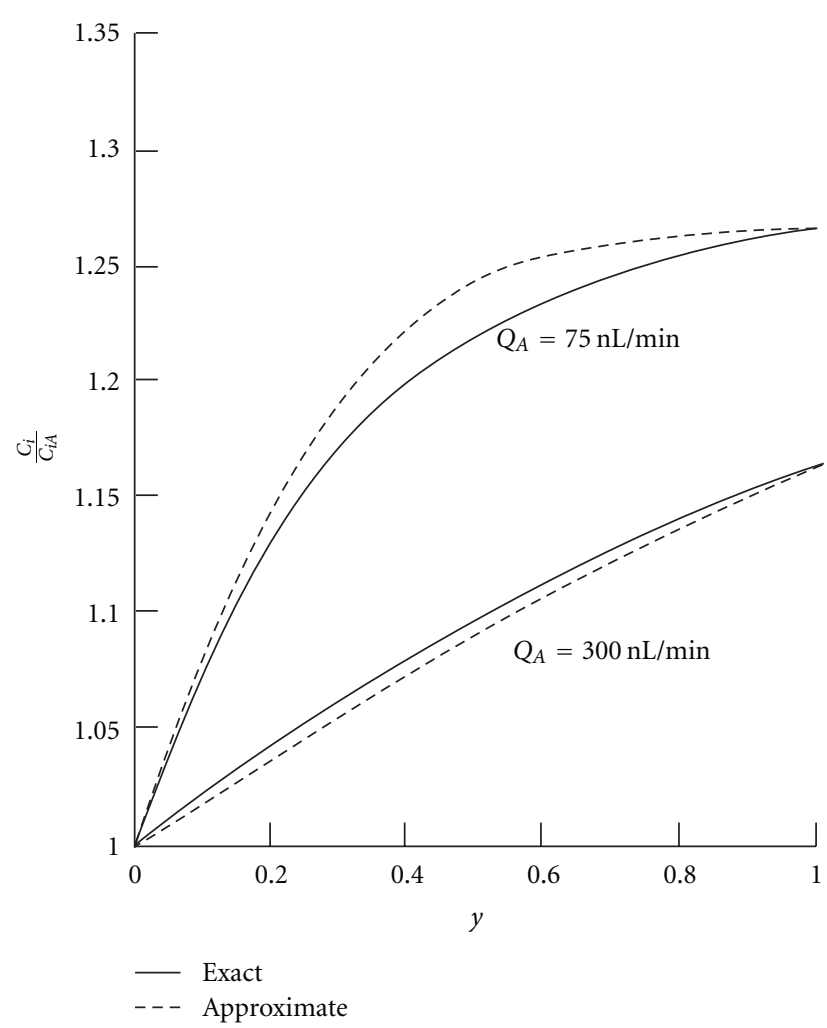

FIGURE 1: Plasma solute concentration, relative to its afferent values $\left(C_{i A}\right)$, along a glomerular capillary at 2 values of plasma flow rates. The "exact" curves were obtained by solving the mass balance and flux equations of an isoporous model; the "approximate" curves were obtained after applying some simplifying assumptions, so that an analytic solution can be obtained for the solute concentration ratio. Redrawn from [1].

3.1. Tubuloglomerular Feedback. The TGF system is a key regulator of glomerular filtration rate and the delivery of water and electrolytes to the distal nephron [13]. The TGF response is initiated by a deviation from a target value of the chloride concentration in the tubular fluid flowing past the macula densa, which is a cluster of specialized cells, located in the renal tubule wall near the end of the thick ascending limb of the loop of Henle. If the macula densa chloride concentration is too low, TGF acts to restore it to target by inducing a vasodilation of the afferent arteriole and increases glomerular filtration pressure. A higher blood pressure in the glomerulus increases single nephron filtration rate (SNGFR) and raises the rate of fluid flow throughout the tubule. In particular, this leads to higher fluid flow rate in the thick ascending limb. Conversely, if the macula densa chloride concentration exceeds the target value, the TGF system reduces glomerular filtration rate, and consequently flow rate into the thick ascending limb. The resulting longer tubular transport time increases $\mathrm{NaCl}$ reabsorption along the thick ascending limb and lowers macula densa chloride concentration. The thick ascending limb actively pumps out $\mathrm{NaCl}$ from tubular fluid into the interstitium. Because the thick ascending limb walls are nearly water impermeable, the active reabsorption of $\mathrm{NaCl}$ is not accompanied by water 


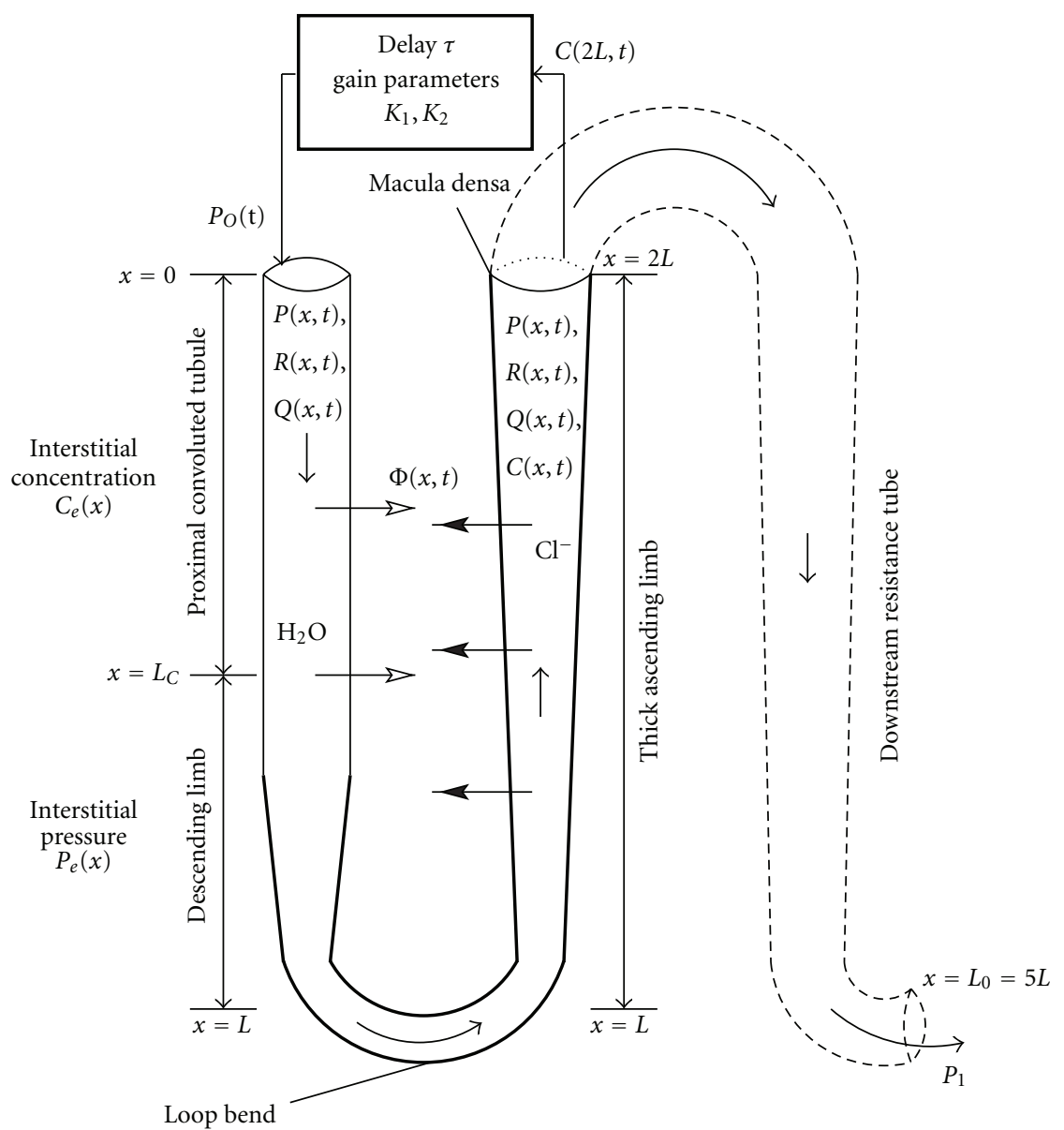

FIGURE 2: Schematic representation model TGF system. Hydrodynamic pressure $P_{o}(t)=P(0, t)$ drives flow into loop entrance $(x=0)$ at time $t$. Oscillations in pressure result in oscillations in loop pressure $P(x, t)$, flow rate $Q(x, t)$, radius $R(x, t)$, and tubular fluid chloride concentration $C(x, t)$. Reprinted from [3].

loss, and the tubular fluid $\mathrm{NaCl}$ concentration progressively decreases along the thick ascending limb. Thus, the thick ascending limb is an important segment of the TGF system, and its transport properties allow it to act as a key operator of the TGF system.

Evidence in experiment has indicated that TGF can mediate sustained, regular oscillations of $\sim 30 \mathrm{mHz}$ in nephron flow and related variables [15]. Modeling studies have been undertaken to understand the emergence of these oscillations. This required the development of time-dependent models of tubule flow and transport. Typically (although there are exceptions, notably [16-18]), TGF models represent the conservation of chloride ion, the concentration of which is believed to be the principal tubular fluid signal for the TGF response [19]:

$$
\begin{aligned}
\pi R^{2} \frac{\partial}{\partial t} C= & -2 \pi R C \frac{\partial}{\partial t} R-Q \frac{\partial}{\partial x} C+C \Phi \\
& -2 \pi R_{s s}\left(\frac{V_{\max } C}{K_{M}+C}+\kappa\left(C-C_{e}\right)\right),
\end{aligned}
$$

where $C$ is the tubular fluid chloride concentration and $C_{e}$ is the time-independent extratubular (interstitial) chloride concentration which is assumed to be fixed. The second component on the right-hand side of the equation represents an axial advective chloride transport at the intratubular flow rate $Q$. $\Phi$ denotes transmural water flux (see below). The two terms inside the large pair of parentheses corresponds to active solute transport characterized by Michaelis-Mentenlike kinetics (with maximum $\mathrm{Cl}^{-}$transport rate $V_{\max }$ and Michaelis constant $K_{M}$ ) and transepithelial $\mathrm{Cl}^{-}$diffusion (with backleak permeability $\kappa$ ). A schematic diagram of the TGF model in [3] is shown in Figure 2 as an example.

Additional model equations are needed to describe tubular fluid dynamics. Some models assume that the renal tubule is a rigid tube with plug flow (e.g., $[11,12,21$, 22]), whereas other represent pressure-drive fluid flow along compliant tubules (e.g., [23-25]); see discussion below. Together with a representation of the TGF response, the model equations can be solved to yield tubular fluid flow and chloride concentration as functions of time and space.

Model studies predict that, for some system parameters, the TGF system can exhibit oscillatory behavior [23, 27]. By linearizing the model equations, Layton et al. [12] derived 


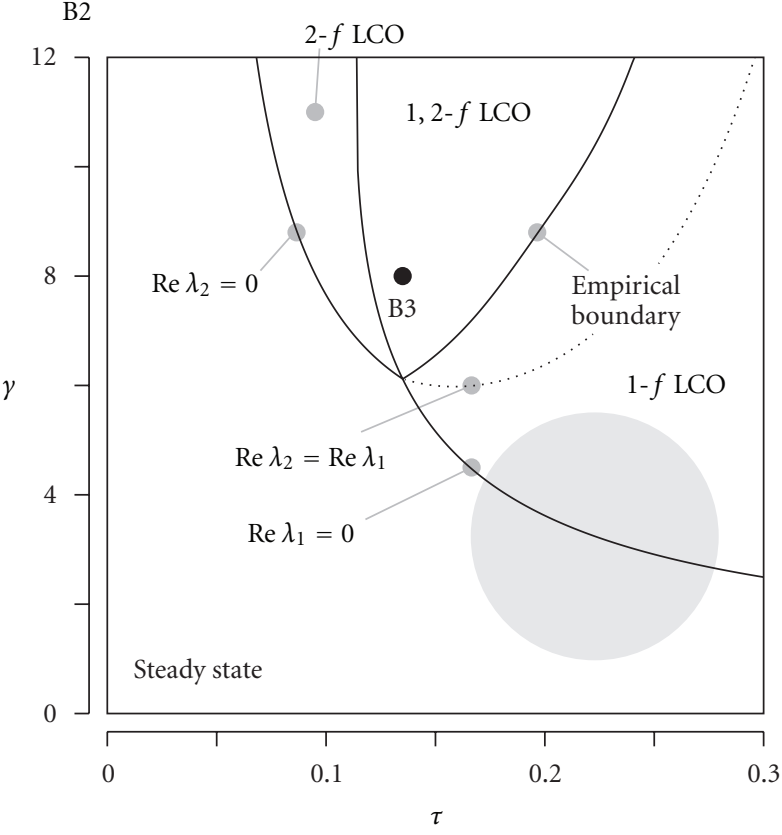

(a)
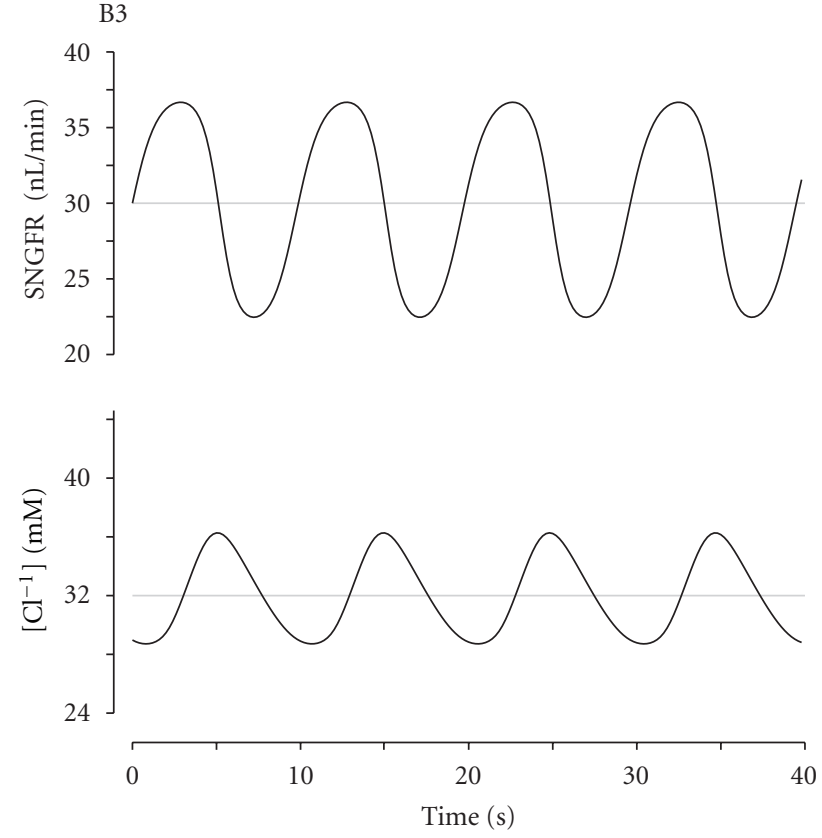

(b)

FIGURE 3: (a): Bifurcation diagrams indicating observed behavior of TGF model solutions. Four qualitatively different model solutions are possible: (1) a regime having one stable, time-independent steady-state solution (labelled "Steady state"), (2) a regime having one stable oscillatory solution only, with fundamental frequency $f$ ("1- $f$ LCO"), (3) a regime having one stable oscillatory solution only, with frequency $\sim 2 f$ (" $2-f$ LCO"), and (4) a regime having two possible stable oscillatory solutions, of frequencies $\sim f$ and $\sim 2 f$ (" $1,2-f$ LCO"). Reprinted from [11]. (b): Oscillations in SNGFR and TAL tubular fluid $\mathrm{CL}^{-}$concentration and at the macula densa obtained using $\tau$ and $\gamma$ values denoted by the point B3.

a characteristic equation that predicts the appearance of TGF-mediated oscillations for different model parameter values within a two-dimensional $(\tau-\gamma)$ parameter space; see Figure 3. The first parameter, $\tau$, is simply the signal delay from macula densa to afferent arteriole. The parameter $\gamma$ is the product of two terms: (a) the steady-state strength of the macula densa signal on thick ascending limb fluid flow and (b) the axial concentration gradient of salt along the ascending limb at the macula densa. This latter term determines how variations in ascending limb flow will be perceived at the macula densa as variations in luminal concentration. These modeling efforts have yielded the conclusion that TGFmediated oscillations arise from a bifurcation: if feedbackloop gain is sufficiently large, then the stable state of the system is a regular oscillation and not a time-independent steady state $[11,12,23,28]$.

The analysis of TGF requires some representation of glomerulus, proximal tubule, and loop of Henle, along with a feedback signal from macula densa to afferent arteriole. However, the details with which each component is represented differ among different models. Model studies by Jensen et al. [16, 17] and by Barfred et al. [18] include explicit representation of the action of the afferent arteriole, whereas other models represent the afferent arteriole response implicitly through the tubular fluid flow rate or pressure $[11,12,28,32]$. For example, a simple model that represents plug flow in rigid tubes may describe the TGF response by assuming the boundary inflow $Q(0, t)$ as a function of time-delayed macula densa chloride concentration $C_{\mathrm{MD}}$ :

$$
Q(0, t)=Q_{o}+K_{1} \tanh \left(K_{2}\left(C_{\mathrm{op}}-C_{\mathrm{MD}}(t-\tau)\right)\right) .
$$

In the above equation, $K_{1}$ denotes half of the range of flow variation around its reference value $Q_{0} ; K_{2}$ quantifies TGF sensitivity; the target concentration $C_{\mathrm{op}}$ is the timeindependent steady-state TAL tubular fluid chloride concentration alongside the macula densa when $Q(0, t)=Q_{o}$ (i.e., when $\left.C_{\mathrm{op}}=C_{\mathrm{MD}}\right) ; C_{\mathrm{MD}}(t-\tau)$ is the chloride concentration alongside the macula densa at the time $t-\tau$, where $\tau$ represents the TGF delay. The TGF response curve assumed in [12] is shown in Figure 4 as an example.

The models by Jensen et al. and by Barfred et al. both employ simple, nonspatially distributed formulations to represent the TAL and its delays-specifically, a linear system of three first-order ordinary differential equations (equations (8) $--(10)$ in [18]). The formulations used in these model studies differ fundamentally from the spatially distributed formulations used by Holstein-Rathlou and Marsh [23] and by Layton and coworkers [12]; these formulations solved the hyperbolic partial differential equation that explicitly represents the advective transport of solute and its coupling with transepithelial active and diffusive transport (e.g., (2)).

In many TGF models (e.g., $[12,23,32,34,35])$, the thick ascending limb is represented in detail, because model 


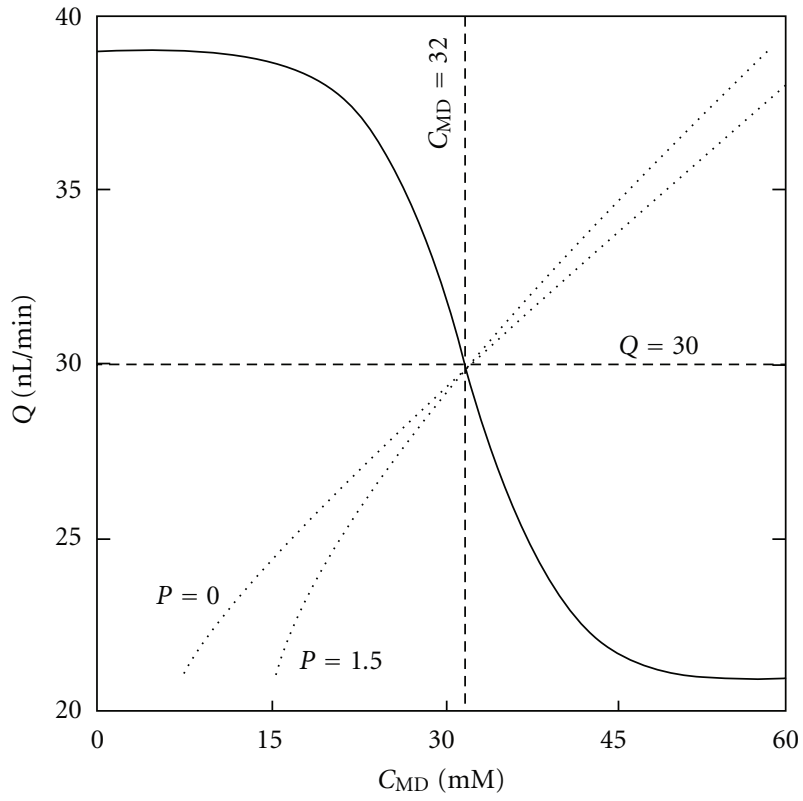

FIGURE 4: Solid curve is feedback response. Dashed curves represent MD chloride concentration as a function of SNGFR, at 0 and $1.5 \times$ $10^{-5} \mathrm{~cm} / \mathrm{s}$ thick ascending limb $\mathrm{NaCl}$ permeability. Redrawn from [12].

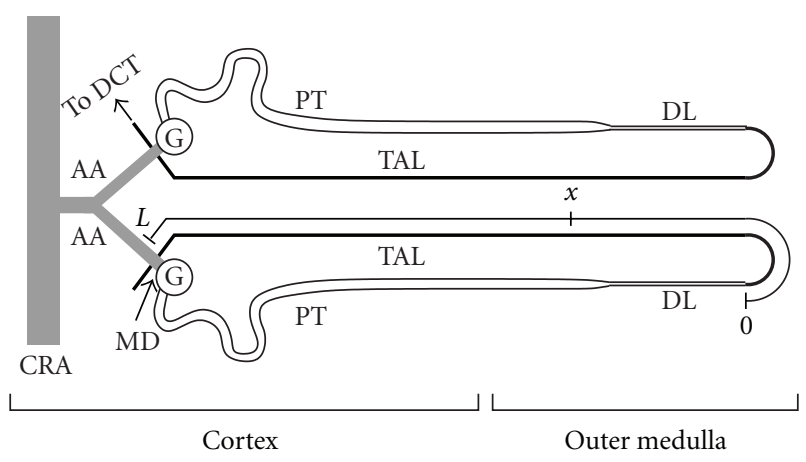

FIGURE 5: A schematic drawing of two short-looped nephrons and their afferent arterioles (AA). The arterioles branch from a small connecting artery (unlabeled), which arises from a cortical radial artery (CRA). The nephron consists of the glomerulus $(\mathrm{G})$ and a tubule having several segments, including the proximal tubule (PT), the descending limb (DL), the thick ascending limb (TAL), and the distal convoluted tubule (DCT). Each nephron has its glomerulus in the renal cortex, and each short-looped rat nephron has a loop that extends into the outer medulla of the kidney. The axis on the TAL of the lower nephron corresponds to the spatial axis used in the model; in this figure distance is indicated in terms of fractional (nondimensional) TAL length. Tubular fluid from the DL flows into the TAL lumen at $x=0$; the chloride concentration of TAL luminal fluid is sensed by the macula densa (MD) at $x=1$. The MD, a localized plaque of specialized cells, forms a portion of the TAL wall that is separated from the AA by a few layers of extraglomerular mesangial cells; in this figure, the MD is part of the short TAL segment that passes behind the AA. Fluid from the DCT enters the collecting duct system (not shown), from which urine ultimately emerges. Structures labeled on one nephron apply to both nephrons. (Figure and legend adapted from [14].) investigations have indicated that the transduction process in the thick ascending limb exhibits a number of features, such as the generation of harmonics that transform sinusoidal waves into waves that are periodic but nonsinusoidal, that may help explain phenomena found in regular and irregular oscillations that are mediated by TGF $[11,21$, 22]. In contrast, other components of the TGF loop were represented in those TGF models by means of simple, phenomenological representations; the actions of the proximal tubule and descending limb of a short-looped nephron were modeled by a linear function that represents glomerulartubular balance in proximal tubule and water absorption from the descending limb [12]. Other TGF models include more detailed representation of the proximal tubular and descending limb $[3,23]$.

Hydrodynamic pressure drives tubular fluid flow, and oscillations in fluid flow, through the tubules of the kidney, including the thick ascending limb. Given that observation, Marsh and collaborators [23-25] developed a mathematical model of the nephron that represents hydrodynamic pressure and compliant tubular walls; simulations from that model predict that a compliant renal tubule will tend to function as a low-pass filter with respect to flow oscillations (Figure 7 in [24]). In contrast, other TGF models represent the thick ascending limb as a rigid tube with plug flow (e.g., [11, 12, $21,22]$ ) and prescribe flow rate in the TAL as a function of predicted SNGFR [36]; hydrodynamic pressure is not computed. Recently, Layton and collaborators extended their TGF models to represent compliant tubular walls [28, 34, 37]:

$$
R(x, t)=\alpha\left(P(x, t)-P_{e}(x)\right)+\beta(x) .
$$

Equation (4) represents a compliant tube, such that its tubular luminal radius varies as a function of transmural pressure difference. $P_{e}(x)$ denotes the extratubular (interstitial) pressure, $\alpha$ specifies the degree of tubular compliance, and $\beta(x)$ is the unpressurized tubular radius. Model results suggest that tubular wall compliance increases the tendency of the TGF system to oscillate.

It has been well documented that TGF systems in neighboring nephrons are coupled and that coupling appears to arise from electrotonic conduction along the preglomerular vasculature [38-40]. A schematic diagram of two shortlooped nephrons coupled through their afferent arterioles is shown in Figure 5. Thus, if two nephrons have afferent arterioles that are nearby on the cortical radial artery, the contraction of one nephron's afferent arteriole tends to result in the contraction of the other nephron's afferent arteriole. To represent a system of $n$ coupled nephrons, the flow equation (3) can be modified to include the influences of neighboring nephrons:

$$
\begin{aligned}
Q_{i}(0, t)= & Q_{o}+K_{1} \tanh \left(K_{2}\left(C_{\mathrm{op}}-C_{\mathrm{MD}}(t-\tau)\right)\right) \\
& +\sum_{j \neq i} \phi_{i j}\left(Q_{j}(0, t)-Q_{o}\right),
\end{aligned}
$$

where $\phi_{i j}$ denotes the coupling strength between nephrons $i$ and $j$. 


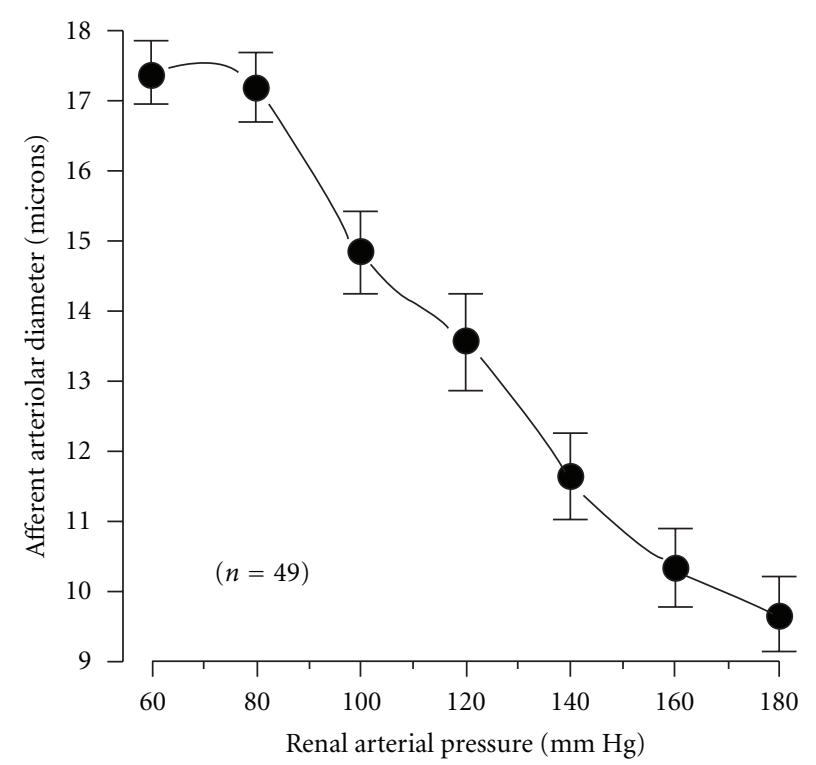

(a)

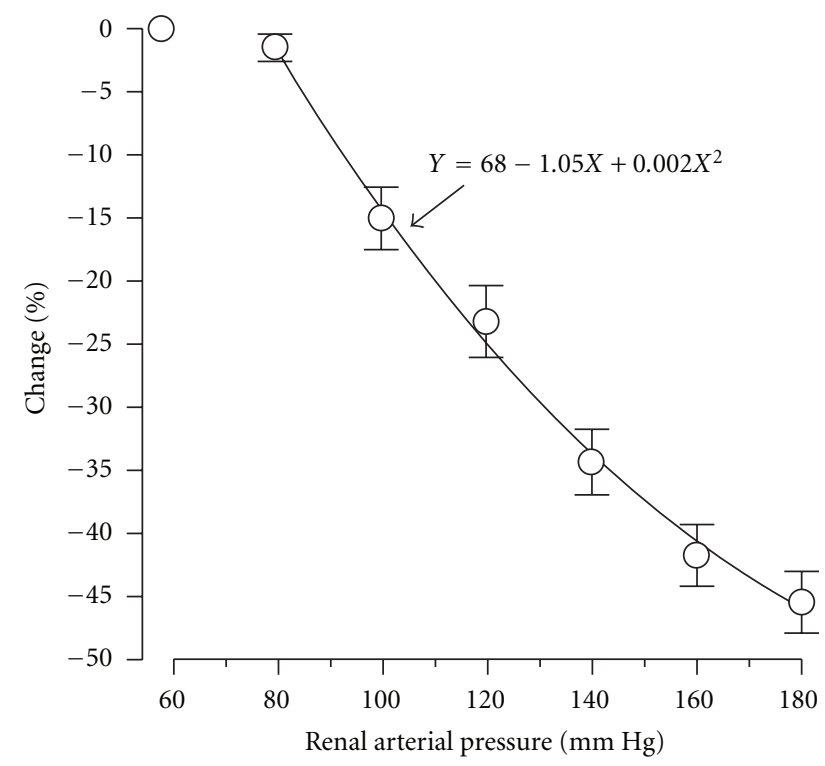

(b)

Figure 6: (a) Steady-state diameter at renal arteriolar pressure of 60 to $180 \mathrm{mmHg}$. (b) Percent change from basal (60 mmHg) diameter, fitted using a simple quadratic equation. Redrawn from [20].

Modeling investigations of coupled nephrons [11, 14, 41, 42] show that differing gains and time delays between coupled nephrons, which merely reflect differences in nephron dimensions and TGF gains, can introduce doublet and triplet spectral peaks into the power spectrum and generate irregular flow oscillations and complex power spectra similar to those observed in spontaneously hypertensive rats. Other studies suggest that internephron coupling may induce synchronization, quasiperiodicity, and perhaps chaos in a nephron tree $[43,44]$.

3.2. Myogenic Mechanism. The myogenic mechanism is an intrinsic property of the afferent arteriole that induces a compensatory vasoconstriction of the afferent arteriole when the vessel is presented with an increase in transmural pressure. Measurements by Loutzenhiser et al. of afferent arteriolar diameter at different perfused pressures are exhibited in Figure 6. The renal afferent arteriole, like most other small arteries and arterioles, exhibits spontaneous rhythmic activity, aka vasomotion. Vasomotion is spontaneous in the sense that vascular tone oscillates independently of heart beat, innervation, or respiration. The driving stimulus of vasomotion is believed to be oscillations of the same frequency intrinsically appearing on the electrical activity of the cells consisting the arteriolar walls. Vasomotion is blocked by the same blockers ( $\mathrm{Ca}^{2+}$ and $\mathrm{K}^{+}$membrane channel blockers) that eliminate the myogenic response which is believed to be functionally related.

Vascular smooth muscle responds to increased stretch with active force development, a phenomenon termed the myogenic response. This response enables arterial blood vessels to constrict as intraluminal pressure increases under physiological conditions. In the arteriolar system, myogenic responses are thought to be important for local autoregulation of blood flow and regulation of capillary pressure.

Based on the kinetic attributes of the afferent arteriole myogenic response and the steady-state pressure and afferent arteriole diameters, Loutzenhiser et al. [20] developed a mathematical model of renal autoregulation. That model is a phenomenological one that predicts vascular responses in terms of arteriolar diameter only, and those appear to be consistent with the dynamic features of renal autoregulation observed in the intact kidney. In a follow-up study, Williamson et al. [46] developed a more extensive systems model to examine the impact of systolic-pressure sensitivity on renal autoregulation. Their results show that the asymmetry in time delays in the myogenic response is more important than differences in the time constants of vasoconstriction versus vasodilation in accounting for the sensitivity to systolic pressure in the hydronephrotic kidney.

Lush and Fray developed a mathematical model of the myogenic control of the afferent arteriole [47] and used that model to study the steady-state autoregulation of renal blood flow in the dog kidney. Their model computes steadystate renal blood flow assuming a balance of the distensive and constrictive forces acting on the afferent arteriole. The afferent arteriole smooth muscle contraction in that model is assumed to be initiated by pressure-induced changes in calcium permeability, and their model describes the effect of transmural pressure on calcium permeability, intracellular calcium concentration, and contractile activity. Because Lush and Fray focused on steady-state autoregulation, details of the kinetics of the afferent arteriole ionic transport and muscle mechanics were not represented nor was the asymmetry in the response times of the afferent arteriole to pressure increase and decrease. Also, individual afferent arteriole cells are not differentiated in that model. 
Carlson and coworkers developed a model of blood flow regulation $[48,49]$. Their model's representations of the active contractile force and resulting muscle mechanics are similar to the model by Lush and Fray [47], but the model by Secomb and coworkers represents also metabolic vasoactive and shear stress-dependent responses. Their model was formulated for both large and small arterioles, each with a different set of parameters.

Layton and collaborators $[29,30]$ developed a mathematical model of the myogenic response of the afferent arteriole, based on an arteriole model by GonzalezFernandez and Ermentrout [50]. The model incorporates ionic transport, cell membrane potential, contraction of the arteriolar smooth muscle cell, and the mechanics of a thickwalled cylinder. The model's representation of the!myogenic response is based on the hypothesis that changes in hydrostatic pressure induce changes in the activity of nonselective cation channels. The resulting changes in membrane potential then affects calcium influx through changes in the activity of the voltage-gated calcium channels, so that vessel diameter decreases with increasing pressure values. Model results suggest that the interaction of $\mathrm{Ca}^{2+}$ and $\mathrm{K}^{+}$fluxes mediated by voltage-gated and voltage-calcium-gated channels, respectively, gives rise to periodicity in the transport of the two ions. This results in a time-periodic cytoplasmic calcium concentration, myosin light chain phosphorylation, and crossbridges formation with the attending muscle stress. A flow chart illustrates the step by which periodic oscillations in cytosolic calcium concentration gives rise to spontaneous vasomotion of the model afferent arteriole is shown in Figure 7(a); oscillations in key model variables are shown in Figures 7(c) and 7(d). Further, the model predicts myogenic responses that agree with experimental observations (see Figure 7(b)), most notably those which demonstrate that the renal AA constricts in response to increases in both steady and systolic blood pressures [29]. Model simulation of vasoconstriction initiated from local stimulation also agrees well with findings in the experimental literature, notably those of Steinhausen et al. [51], which indicated that conduction of vasoconstrictive response decays more rapidly in the upstream flow direction than downstream. Marsh et al. [52] also adopted the smooth muscle cell model of GonzalezFernandez and Ermentrout [50] to study the interactions between afferent arteriole myogenic response and TGF.

\section{How Does the Kidney Produce a Highly Concentrated Urine?}

When deprived of water, the kidney of a mammal can conserve water by increasing the solute concentration (or, osmolality) in the urine to a level well above that of the blood. This process of urine concentration occurs in the renal medulla and has the effect of stabilizing the osmolality of blood plasma. Such urine, which is said to be hypertonic, is concentrated in the final stages of urine production; water is absorbed, in excess of solute, from the collecting ducts and into the vasculature of the medulla, thus increasing the
TAble 1: Maximum measured urine osmolalities in selected animals. For comparison, blood plasma osmolality is about $300 \mathrm{mosm} / \mathrm{kg} \mathrm{H}_{2} \mathrm{O}$ [26].

\begin{tabular}{lc}
\hline Animal & $\begin{array}{c}\text { Urine osmolality } \\
\text { mosm } / \mathrm{kg} \mathrm{H}_{2} \mathrm{O}\end{array}$ \\
\hline Domestic pig & 1,075 \\
Human & 1,430 \\
Rat & 2,849 \\
Mouse & 2,950 \\
Chinchilla & 7,599 \\
Australian hopping mouse & 9,374 \\
\hline
\end{tabular}

osmolality of the collecting duct fluid-fluid that is called urine after it emerges from the collecting ducts.

Some animals can concentrate urine better than others. Maximum reported urine osmolalities in several animals are shown in Table 1. For comparison, blood plasma osmolality is $\sim 300 \mathrm{mosm} / \mathrm{kg} \mathrm{H}_{2} \mathrm{O}$. That means the human kidney can produce a urine that is $\sim 4.8$ times that of plasma. Note that this is the maximum value ever measured, so it is fair to say that most of us do not do that well. That human maximum urine osmolality value is also the reason that one should refrain from drinking sea water to quench thirst, given that sea water osmolality ranges from 2,000 to 2,400 mosm $/ \mathrm{kg}$ $\mathrm{H}_{2} \mathrm{O}$. The kidney of an Australian hopping mouse, which lives in the desert, can produce an amazingly concentrated urine that has an osmolality $>30$ times that of blood plasma.

In the outer medulla of the rat kidney, water absorption from collecting ducts is driven by active transepithelial transport of $\mathrm{NaCl}$ from the water-impermeable thick ascending limbs into the surrounding interstitium, where the $\mathrm{NaCl}$ promotes, via osmosis, water absorption from collecting ducts, descending limbs, and some blood vessels. The countercurrent configuration of renal tubules and blood vessels in the outer medulla augments this concentrating effect, as a function of depth, along the corticomedullary axis; in a process called "countercurrent multiplication," an osmolality gradient is generated along all structures of the outer medulla, from the corticomedullary boundary to the outer-inner medullary boundary. The paradigm of countercurrent multiplication was proposed by Kuhn and Ryffel in 1942 [53]. They hypothesized that an osmolality gradient could be generated along parallel but opposing flows in adjacent tubes that are made contiguous by a hairpin turn (Figure 8): a transfer of solute from one tubule to another (a "single" effect) augments ("multiplies," or reinforces) the axial osmolality gradient in the parallel flows ("Vervielfältigung des Einzeleffektes"). Thus, a small transverse osmolality difference (a small single effect) is multiplied into a much larger osmolality difference along the axis of tubular flow. In support of this paradigm, Kuhn and Ryffel constructed an apparatus that exemplified the principle of countercurrent multiplication [53].

Although this concentrating mechanism is well established in the outer medulla-by both physiological experiments and theoretical investigation-the nature of the concentrating mechanism in the inner medulla, where the 


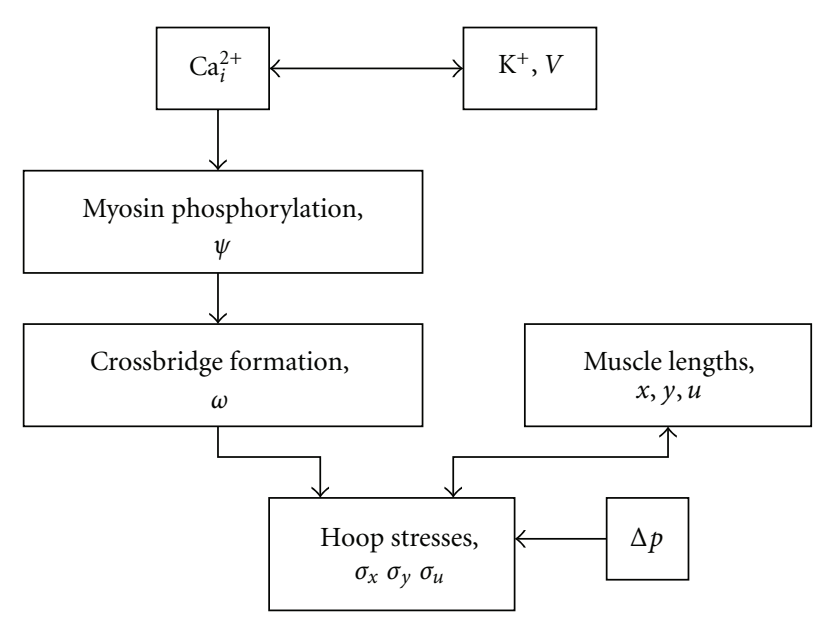

(a)

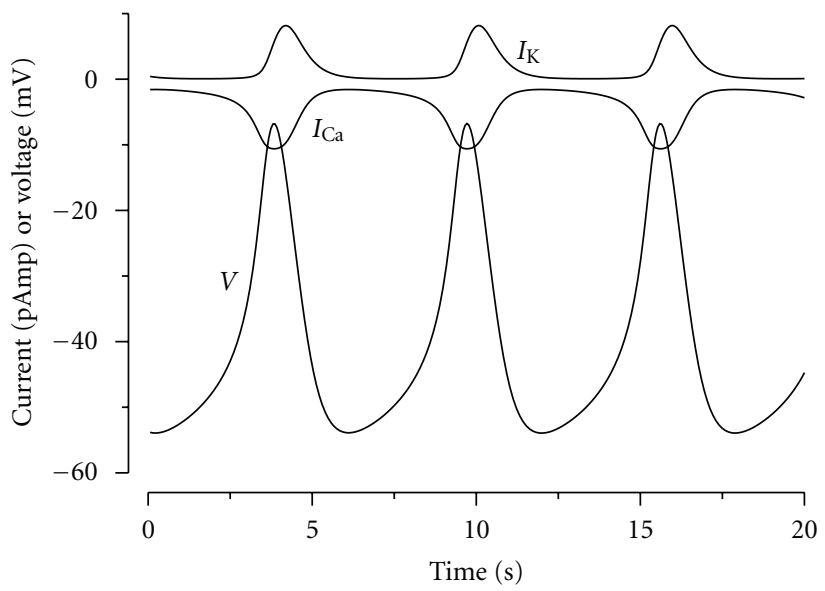

(c)

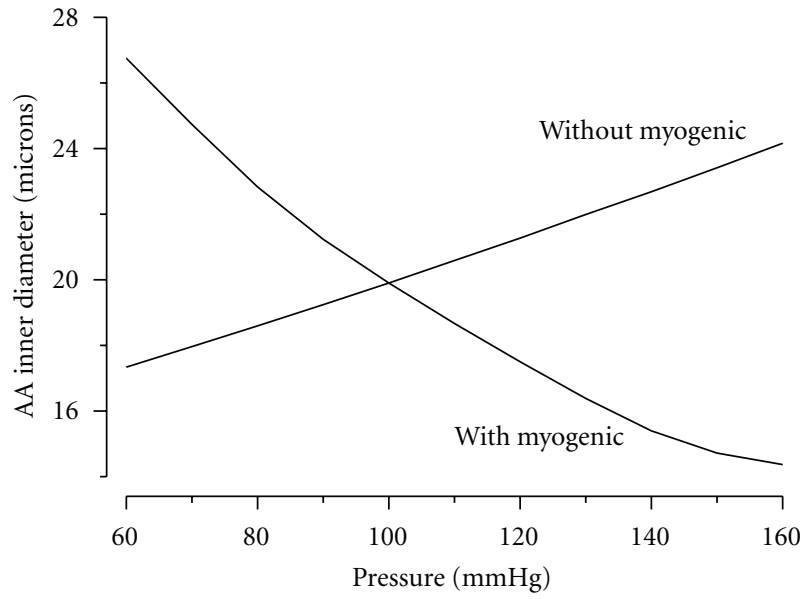

(b)

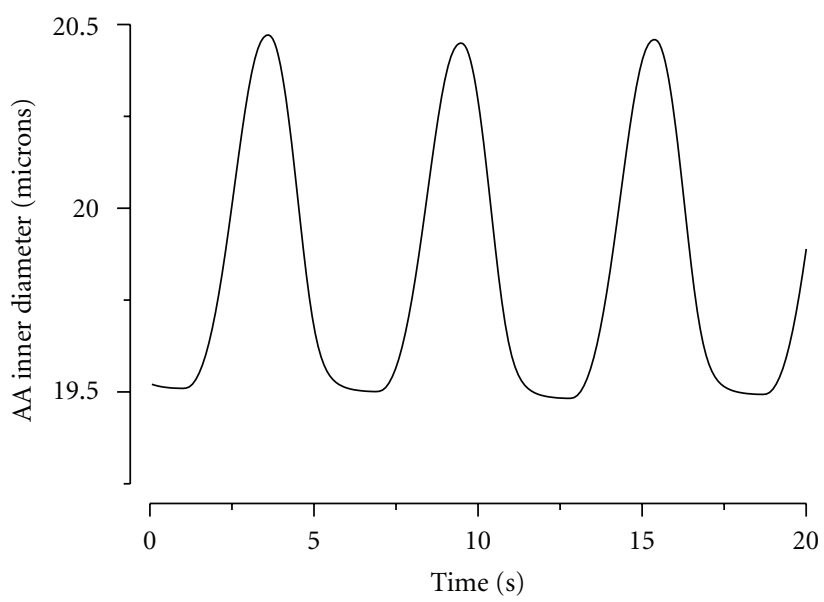

(d)

Figure 7: (a) A flow chart that illustrates the steps by which periodic oscillations in cytosolic calcium concentration give rise to spontaneous vasomotion of the model afferent arteriole in $[29,30]$. (b) Average vessel inner diameter as a function of steady-state transmural pressure, with and without a myogenic response. (c) Oscillations in $\mathrm{Ca}^{2+}$ and $\mathrm{K}^{+}$currents (denoted $I_{\mathrm{Ca}}$ and $I_{\mathrm{K}}$, resp.) and membrane potential $v$. (d) Oscillations in intracellular arteriolar inner diameter. Reprinted from [29].

concentrating effect is the largest in some mammals, remains to be elucidated. For details on current understandings of the mammalian urine concentrating mechanism, see reviews $[31,54,55]$.

Steady-state urine concentrating mechanism models typically consists of ODEs that describe water and solute conservation:

$$
\begin{aligned}
\frac{\partial}{\partial x} Q(x) & =J_{v}(x), \\
\frac{\partial}{\partial x}\left(Q(x) C_{k}(x)\right) & =J_{k}(x),
\end{aligned}
$$

where $Q$ denotes tubular water flow rate, $J_{v}$ denotes water flux through the tubular walls, taken positive into the tubules, $C_{k}$ denotes the concentration of the $k$ th solute, and $J_{k}$ denotes its transmural flux.
Urine concentrating mechanism models typically assumes single-barrier transport. Water flux into a renal tubule can be described by

$$
J_{v}(x)=2 \pi r(x) L_{p}\left(\Delta P+R T \sum_{k} \phi_{k}\left(C_{k}(x)-C_{k}^{e}(x)\right)\right),
$$

where $L_{p}$ is the water permeability of the tubule, $\Delta P$ denotes the hydrostatic pressure gradient, $\phi_{k}$ denotes the osmotic coefficient, and $C_{k}^{e}(x)$ denotes the interstitial concentration of the $k$ th solute.

A typical model describes two pathways by which a solute may be transported across renal tubular walls, passive, and active:

$$
J_{k}(x)=2 \pi r(x)\left(\frac{-V_{\max }(x) C_{k}(x)}{K_{M}+C_{k}(x)}+P_{k}(x)\left(C_{k}^{e}(x)-C_{k}(x)\right)\right) .
$$




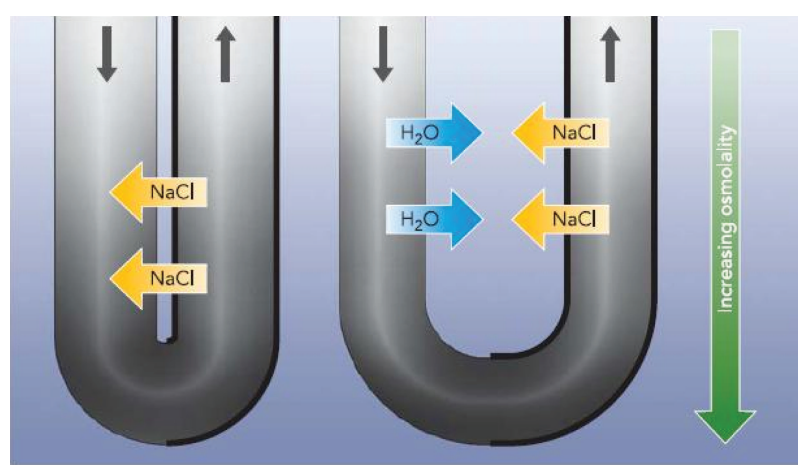

Counter current multiplication

FIGURE 8: The original formulation of the countercurrent multiplication, where the descending and ascending tubes are in direct contact, and $\mathrm{NaCl}$ is transported from the descending tube to the ascending tube. Reprinted from [31].

The first term on the right represents active solute transport, which is characterized by Michaelis-Menten kinetics, with maximum transport rate $V_{\max }$ and Michaelis constant $K_{M}$. The second term represents transmural diffusion, with solute permeability $P_{k}$.

Hoppensteadt and Peskin [56] presented a simple model of the loop of Henle that exemplified the countercurrent multiplication that may take place between the descending and ascending limbs of the loop. Their model assumes that $\mathrm{NaCl}$ is actively pumped out of the ascending limb, and water is reabsorbed from the water-permeable descending limb. The limbs interact through an external compartment, which represents the peritubular capillaries. The model assumes that the reabsorbate (i.e., $\mathrm{NaCl}$ from the ascending limb and water from the descending limb) is picked up locally, that is, axial flow is not allowed in this compartment. The collecting duct is not represented in this model, although an extension to include a collecting duct is straightforward. Owing to the simplicity of this model, analytical solution can be derived to relate the concentrating effect (loop-bend concentration) to active $\mathrm{NaCl}$ transport rate or loop length.

Because the Hoppensteadt and Peskin model [56] assumes that there is no axial flow outside of the loop, water and solute absorbed from tubules into the interstitium enter the peritubular capillaries directly, at each medullary level, and afterward, that absorbate was assumed to have no further interaction with the medulla. Consequently, relatively concentrated ascending fluid does not equilibrate with progressively less concentrated surrounding interstitium. And as a result, that model may be unrealistically dissipative of the axial osmolality gradient. An alternative model formulation is the central core assumption, developed by Stephenson [57]. In the central core formulation, blood vessels, the interstitial cells, and the interstitial spaces are merged into a single tubular compartment, in which the loops of Henle and collecting ducts interact. Axial flow is allowed within the central core. The central core formulation assumes maximum countercurrent exchange by the vasculature and is thought to be least dissipative of the axial osmolality gradient. A schematic diagram of the central core model is shown in Figure 9.

The central core formulation was used in urine concentrating mechanism models of the rat kidney [58-67] and of the avian (quail) kidney [68-70]. While birds and mammals can regulate blood plasma osmolality by producing a concentrated urine when deprived of water, the avian kidney differs from the mammalian one in that all the ascending limbs of the avian loop of Henle have active transepithelial transport of $\mathrm{NaCl}$, whereas only the thick ascending limbs in the outer medulla of the mammalian kidney have significant active $\mathrm{NaCl}$ transport. Thus, the avian urine concentrating mechanism is relatively well understood, and the mathematical models [68-70] predicted tubular fluid concentrations that are consistent with experimental measurements in Gambel's quail [71]. In contrast, the thin ascending limbs found in the inner medulla have no significant active transepithelial transport of $\mathrm{NaCl}$ or of any other solute [72-75]. Thus, active solute transport coupled with countercurrent flow does not explain the concentrating process in this region, where the steepest osmotic gradient is generated.

The most influential theory for the generation of the inner medullary osmolality gradient is the "passive mechanism" hypothesis, proposed independently in 1972 by Kokko and Rector [76] and by Stephenson [57]. The passive mechanism depends on the assumption that the interstitium has a much higher urea concentration than $\mathrm{NaCl}$ concentration and that fluid in the ascending limbs has a much higher $\mathrm{NaCl}$ concentration than urea concentration. If the ascending thin limb has a sufficiently high permeability to $\mathrm{NaCl}$, and a sufficiently low permeability to urea, then much $\mathrm{NaCl}$ will diffuse (passively) from the ascending thin limb lumen into the interstitium, while simultaneously little urea will diffuse from the interstitium into the thin limb lumen. If the transepithelial concentration differences are sustained, the interstitial fluid will be concentrated while the luminal fluid is being diluted. The passive mechanism hypothesis assumes that the concentrations are sustained by continuous diffusion of urea from the collecting duct lumen and by continuous delivery of tubular fluid having a high $\mathrm{NaCl}$ concentration to the ascending thin limb; this delivery depends on the descending thin limb having sufficiently low $\mathrm{NaCl}$ and urea permeabilities that transepithelial concentration gradients are not dissipated along the course of the descending thin limbs. Thus, the passive mechanism is critically dependent on specific loop-of-Henle permeabilities to $\mathrm{NaCl}$ and urea.

However, mathematical models using measured values of urea permeability have generally been unable to predict a significant axial osmolality gradient [54]. Indeed, unless idealized tubular transport properties are used, central core models of the rat kidney fail to produce substantial concentrating effect [62]. The inconsistency between measured urine osmolalities and the predictions of mathematical models has motivated the formulation of a number of alternative hypotheses, extensively reviewed in [77].

One attempt to salvage the passive hypothesis is by means of representation of the preferential interactions that arise from three-dimensional medullary structure [78-80]. 


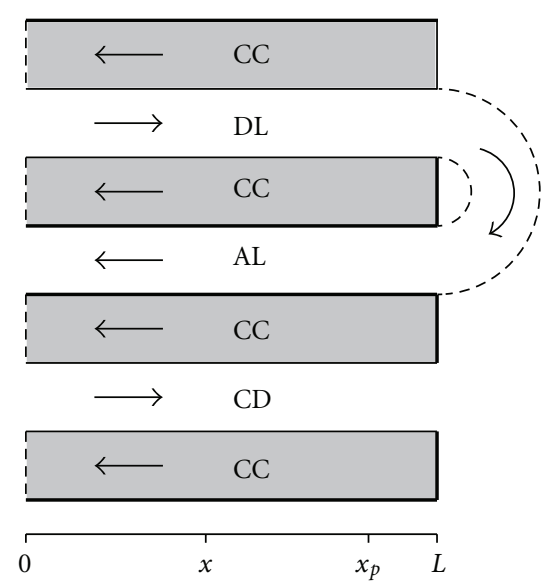

(a)

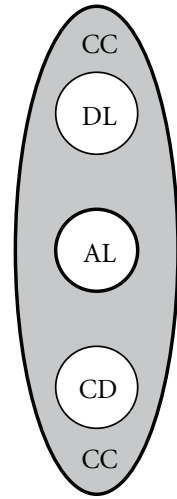

(b)

Figure 9: Schematic diagram of the central core model. (a): Tubules along spatial axis. DL, descending limb; AL, ascending limb; CD, collecting duct; CC, central core. Arrows, steady-state flow directions. Heavy lines, water-impermeable boundaries. (b): Cross-section showing connectivity between CC and other tubules. Modified from [33].

Both the Hoppensteadt and Peskin model [56] and the central core model [57] assume that solute concentrations are uniform at each medullary level, that is, tubules (and blood vessels, if represented) were assumed to interact with each other through a common surrounding medium in which solute concentrations varied only along the corticomedullary axis. However, this assumption appears to be inconsistent with anatomical studies. A number of investigators, notably Kriz and colleagues, have reported that the medullary organization of tubules and vessels is highly structured in a number of mammals [81] including rats and mice [82-84]. Descending and ascending vasa recta form tightly packed vascular bundles that appear to dominate the histotopography of the outer medulla, especially in the inner stripe. Throughout the outer medulla, collecting ducts are found distant from vascular bundles, whereas the loops of Henle are positioned nearer the bundles. Recent anatomic studies of three-dimensional architecture of rat inner medulla and expression of membrane proteins associated with fluid and solute transport in nephrons and vasculature have revealed transport and structural properties that likely impact the inner medullary urine concentrating mechanism in the rat kidney. These studies have shown that the inner medullary portion of the descending limbs have at least two or three functionally distinct subsegments and that clusters of collecting ducts form the organizing motif through the first $3-3.5 \mathrm{~mm}$ of the inner medulla [85-87]. Schematic diagrams of tubular organization in the rat renal medulla are shown in Figure 10 for the inner stripe and upper inner medulla. The structural organization is believed to result in preferential interactions among tubules and vasa recta, interactions that may contribute to more efficient countercurrent exchange or multiplication, to urea cycling and inner medullary urea accumulation, and to sequestration of urea or $\mathrm{NaCl}$ in particular tubular or vascular segments [78, 80, 88-93].

Several investigators have sought to represent aspects of three-dimensional medullary structure in mathematical models of the urine concentrating mechanism. Knepper et al. [94] and Chandhoke and Saidel [95] separated the vasculature and the tubules of the outer medulla into two separate compartments. In the early 90 s, Wexler et al. [80, 96] developed a model (the "WKM" model) that represented a very substantial degree of structural organization by means of weighted connections between tubules and vessels. Although the WKM model was formulated primarily to investigate the concentrating mechanism of the inner medulla, outer medullary function played a large role in both the original [80] and subsequent WKM studies [78, 97].

More recently, Layton and coworkers developed highdetailed mathematical models for the rat kidney's concentrating mechanism. To represent the radial distribution of tubules and vasa recta, with respect to the vascular bundle, the model uses a "region-based" configuration; see Figure 11. The renal medullas are separated into regions, and radial structure is incorporated by assigning appropriate tubules and vasa recta (or fractions thereof) to each concentric region. The region-based approached was used to first develop a model of the rat outer medulla [98-100] and then used in a series of models of the rat renal medulla $[45,101,102]$.

As previously noted, it has become widely accepted that the osmolality gradient along the corticomedullary axis of the mammalian outer medulla is generated and sustained by a process of countercurrent multiplication (see Figure 8): active $\mathrm{NaCl}$ absorption from thick ascending limbs is coupled with the counter-flow configuration of the descending and ascending limbs of the loops of Henle to generate an axial osmotic gradient along the outer medulla. However, simulations using the region-based model suggest that countercurrent multiplication may not explain the axial osmolality gradient in the outer medulla. Aspects of anatomic structure (e.g., the physical separation of the descending limbs of short loops of Henle from contiguous ascending limbs), recent physiologic experiments (e.g., those which suggest 


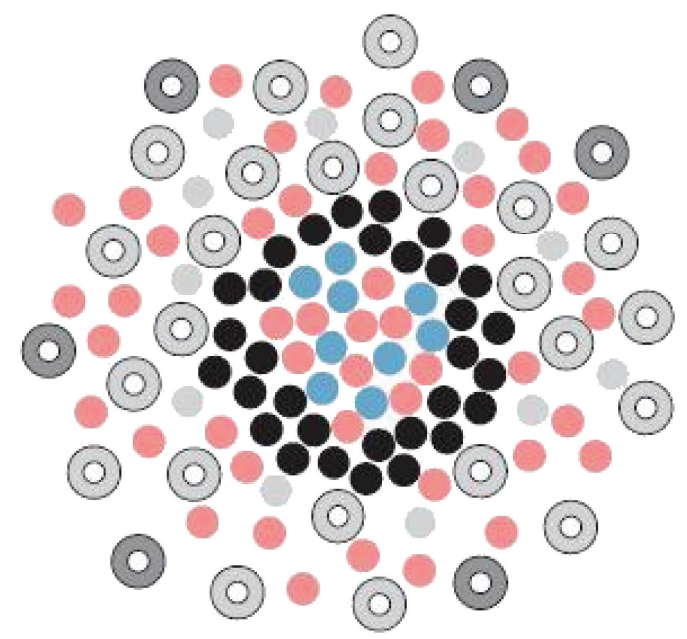
Short descending limb
(O) Collecting duct
Long descending limb
Descending vas rectum
D Dollecting duct
(O) Thick ascending limb
Ascending vas rectum
Ascending thin limb

(a) Inner stripe

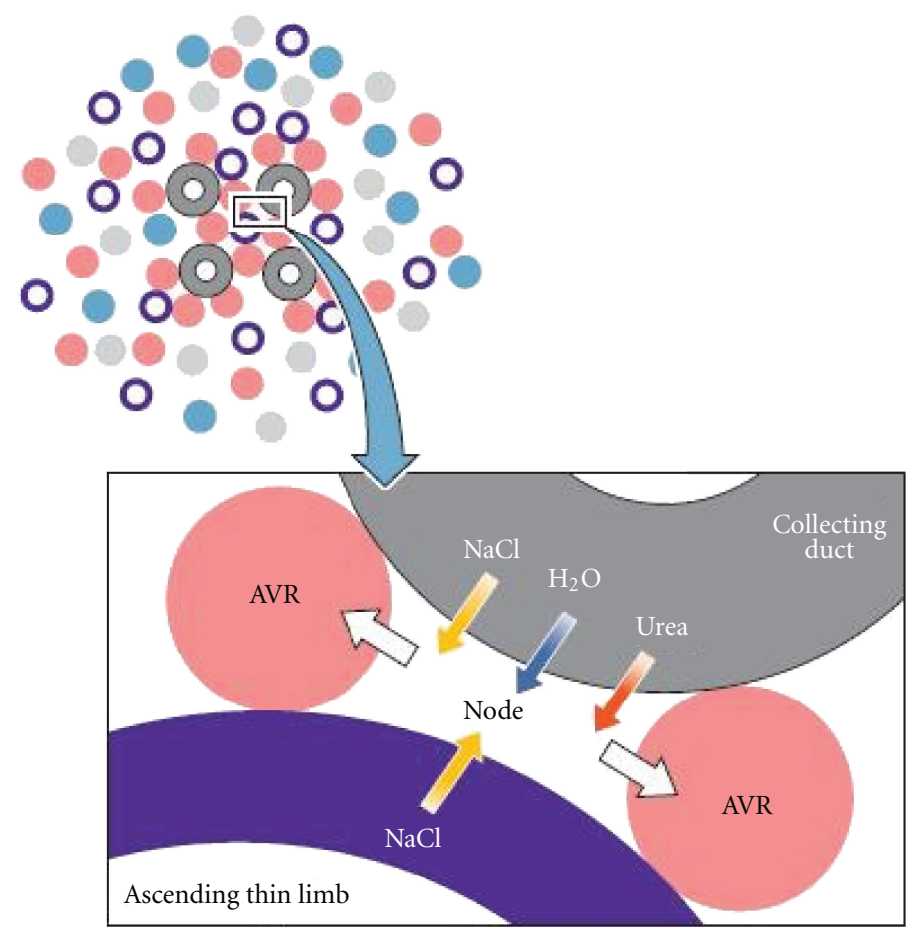

(b) Upper IM

FIGURE 10: Schematic diagrams of tubular organization in the rat renal medulla. (a): Cross-section through the inner stripe of outer medulla, where tubules appear to be organized around a vascular bundle. (b) Cross section through the upper inner medulla, where tubules and vessels are organized around a collecting duct cluster. Inset: schematic configuration of a collecting duct, ascending vasa recta (AVR), an ascending thin limb, and a nodal space. Reprinted from [31]. 


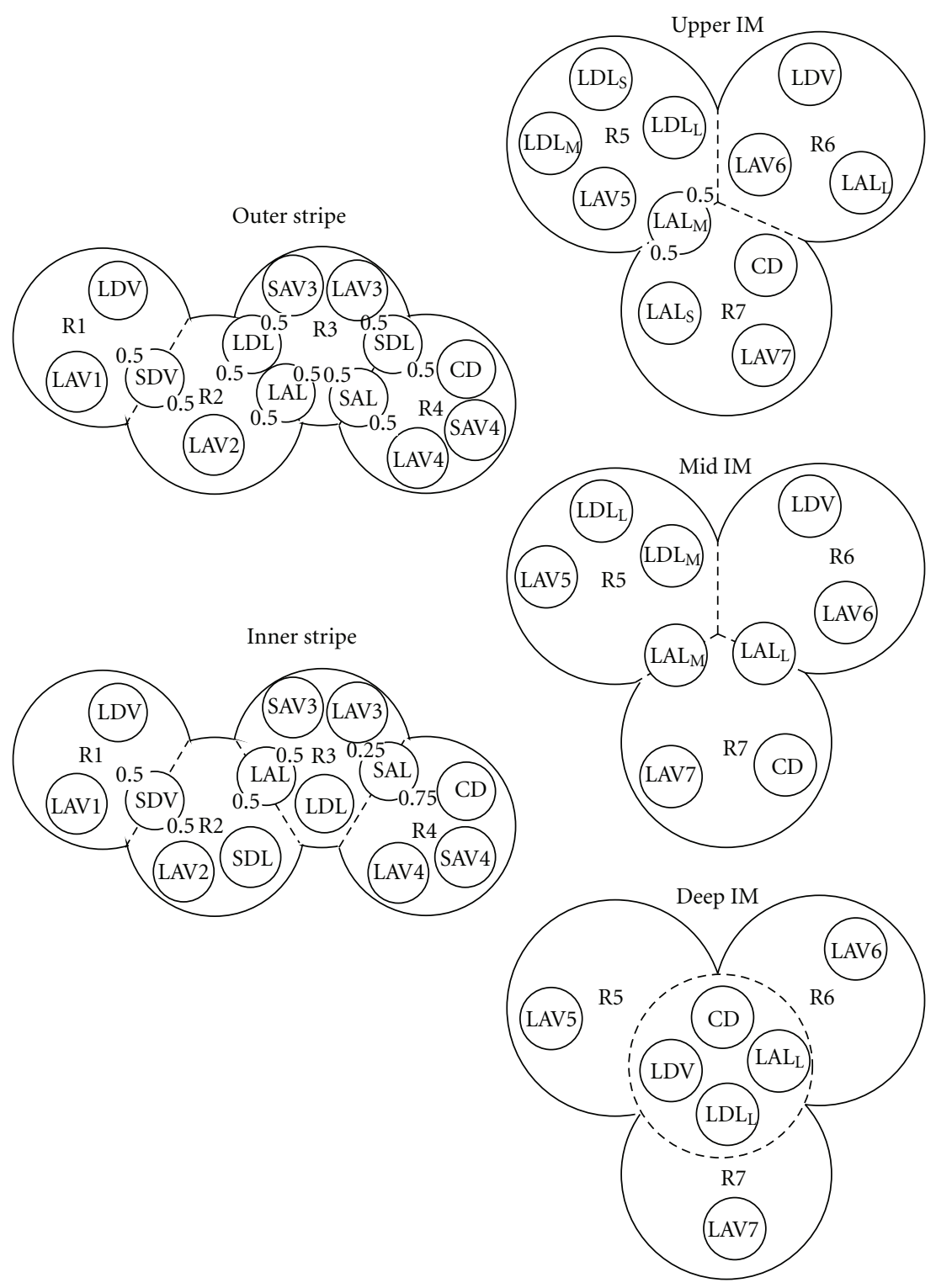

FIGURE 11: Schematic diagram of a cross section through the outer stripe, inner stripe, upper inner medulla (IM), mid IM, and deep IM, showing regions and relative positions of tubules and vessels. Decimal numbers indicate relative interaction weightings with regions. R1, R2, R3, and R4, regions in the outer medulla; R5, R6, and R7, regions in the IM. SDL, descending limbs of short loops of Henle. SAL, ascending limbs of long loops of Henle. LDL, descending limb of long loop of Henle. LAL, ascending limb of long loop of Henle. Subscripts "S," "M," and "L" associated with an LDL or LAL denote limbs that turn with the first mm of the IM (S), within the mid IM (M), or reach into the deep IM (L). CD, collecting duct. SDV, short descending vasa recta. SAV3 and SAV4, two populations of short ascending vasa recta. LDV, long descending vas rectum. LAV1, LAV2, .., LAV7, populations of long ascending vasa recta. Reprinted from [45].

that the thin descending limbs of short loops of Henle have a low water permeability), and mathematical modeling studies (e.g., those which predict that water-permeable descending limbs of short loops are not required for the generation of an axial osmolality gradient [98]) suggest that countercurrent multiplication may be an incomplete, or perhaps even erroneous, explanation. A. T. Layton and H. E. Layton [100] propose an alternative explanation for the axial osmolality gradient: they regard the thick limbs as $\mathrm{NaCl}$ sources for the surrounding interstitium, and they hypothesize that the increasing axial osmolality gradient along the outer medulla is primarily sustained by an increasing ratio, as a function of increasing medullary depth, of $\mathrm{NaCl}$ absorption (from thick limbs) to water absorption (from thin descending limbs of long loops of Henle, and, in antidiuresis, from collecting ducts). They further hypothesize that ascending vasa recta that are external to vascular bundles will carry, toward the cortex, an absorbate that at each medullary level is hyperosmotic relative to the adjacent interstitium. A schematic diagram of this hypothesis is shown in Figure 12.

Based on the anatomical findings that distinguish long loops of Henle into three subpopulations with different 


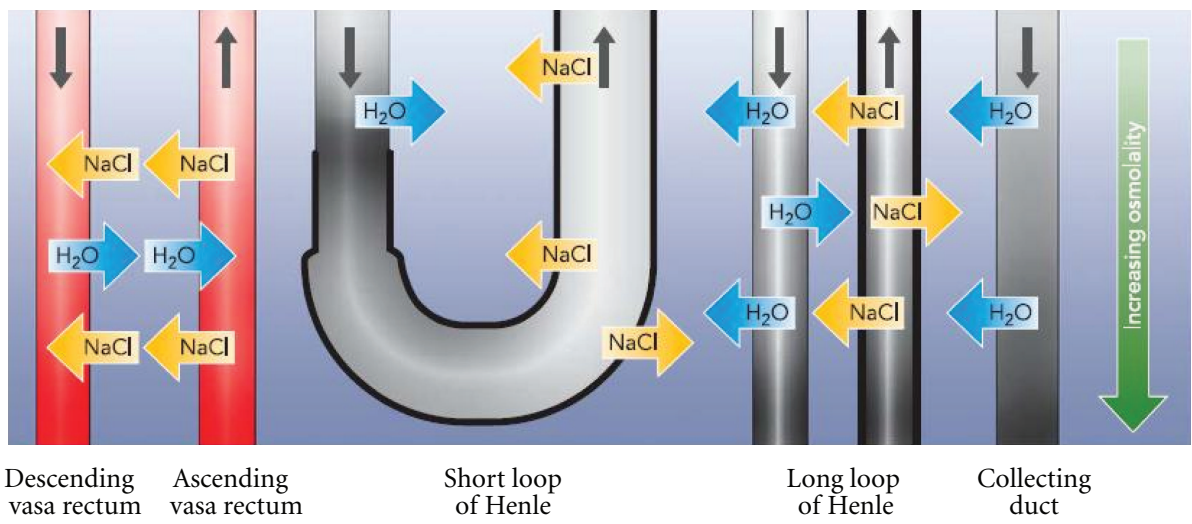

OM concentrating mechanism

(a)

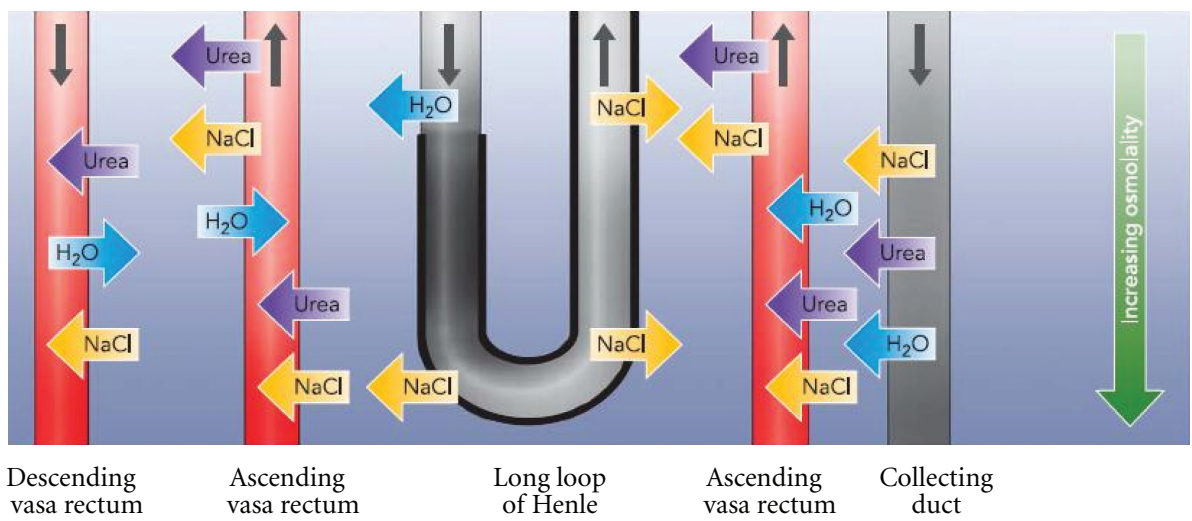

IM concentrating mechanism

(b)

FIGURE 12: A Revised view of countercurrent multiplication as applied to a loop of Henle is shown, where the descending and ascending limbs are separated by the interstitium, and the descending limb fluid is concentrated by water absorption. (a) The concentrating mechanism in the outer medulla, which does not conform to the standard interpretation of the countercurrent multiplication. (b) The concentrating mechanism in the inner medulla, based on the "solute-separation, solute-mixing" mechanism. In all panels, thick lines indicate waterimpermeable portions of tubules; darkening colors represent increasing osmolality. Reprinted from [31].

transport properties [103], and on the radial organization of the loops and vasa recta around collecting duct clusters, Layton and collaborators develop region-based models [45, $58,101]$ that suggest that the inner medullary concentrating processes may be accomplished in stages that can be associated with four subsections, or zones: (1) an outermost zone of $1 \mathrm{~mm}$ thickness, just below the outer medulla, where loops expressing negligible or no AQP-1 have their bends; (2) a larger outer zone, just below the outermost zone, $2-2.5 \mathrm{~mm}$ in thickness, which contains well-organized collecting duct clusters where tubules and vessels are tightly packed and where loops bend within the central portions of the clusters; (3) an outer-inner zone where the organization of the collecting duct clusters is diminishing and all vasa recta are fenestrated; (4) an innermost zone where collecting duct clusters can no longer be distinguished, where the collecting ducts appear to dominate all other structures, where all vasa recta are fenestrated and where a large fraction of loops have substantial transversely running segments. The two inner zones make up the $1.5-2 \mathrm{~mm}$ of the papilla.

\section{How Does the Kidney Regulate Oxygen?}

The availability of oxygen is relatively abundant in the cortex of the rat kidney, with an oxygen tension of $\sim 40$ $50 \mathrm{mmHg}$, but becomes quite low in the medulla, with oxygen tension ranges from $\sim 20 \mathrm{mmHg}$ in the outer medulla to $\sim 10 \mathrm{mmHg}$ in the inner medulla [104]. Low medullary oxygen availability results from the high metabolic requirements of medullary thick ascending limbs, which consumes oxygen and energy to actively pump $\mathrm{NaCl}$ against a concentration gradient, and the countercurrent arrangement of blood vessels in the medulla. The countercurrent architecture, combined with low medullary blood flow (IM blood flow is $<1 \%$ of total renal blood flow [105]), serves to preserve 
the corticomedullary tubular and vascular fluid osmolality gradient that is necessary for the production of concentrated urine, but the concomitant shunting of oxygen between descending and ascending vessels and limbs significantly reduces oxygen supply to the deep medulla.

Evans et al. [106] recently argued that arterial-to-venous (AV) oxygen shunting could play an important role in the dynamic regulation of kidney oxygenation as well as the development of renal hypoxia in kidney disease. They proposed that blood flow-dependent changes in AV oxygen shunting may explain why renal oxygen tension stable when renal blood flow is varied within physiological ranges ( $\pm 30 \%$ relative to basal levels) and oxygen consumption does not vary significantly. They developed a model of oxygen transport in the renal cortex [107]. The model consists of a multiscale hierarchy of 11 countercurrent systems representing the various branch levels of the cortical vasculature. Their model predicts that cortical AV oxygen shunting limits the change in oxygen delivery to cortical tissue and stabilizes tissue oxygen tension when arterial oxygen tension changes, but renders the cortex and perhaps also the medulla susceptible to hypoxia when oxygen delivery falls or consumption increases.

Zhang and Edwards developed an oxygen transport model of the vasa recta in the renal medulla, and modeling results from that study suggest that countercurrent arrangement of DVR and AVR in the medulla results in oxygen shunting from descending vasa recta to ascending vasa recta [108], similar to AV oxygen shunting in the cortex, and significantly limits oxygen delivery to the deep medulla.

Detailed models of oxygen transport in the outer medulla by Edwards and coworkers [109-111] suggest that the structural organization of the outer medulla results in significant oxygen tension gradients in both the axial and radial directions. Their models are based on the region-based urine concentrating mechanism model of the outer medulla by A. T. Layton and H. E. Layton [98]. The segregation of descending vasa recta, the main supply of oxygen, at the center and immediate periphery of the vascular bundles limits oxygen reabsorption from descending vasa recta that reach into the inner medulla, thereby preserving oxygen delivery to the inner medulla but severely restricting oxygen distribution to the interbundle region where thick ascending limbs are located. The model predicts that, as a result, the concentrating capacity of the outer medulla is significantly reduced. The oxygen transport models were subsequently extended to represent nitric oxide and its scavenger superoxide $[112,113]$, both of which modulate renal medullary vascular and tubular function, albeit in opposite ways.

\section{Conclusions}

Mathematical models of renal transport have significantly enhanced our understanding of kidney function and dysfunction. Further modeling efforts, combined with advances in experimental techniques, have the potential of bringing further progress in the understanding of renal function. Indeed, modeling studies have frequently indicated in vivo or in vitro experimental measurements that are needed to facilitate continued progress.

This paper covers mathematical models developed for a number of aspects of kidney physiology. One class of mathematical models that are outside the scope of this paper are models of epithelial transport. For those models, the reader is referred to a review by Weinstein [114] and the references therein.

\section{Acknowledgments}

This paper was supported by the National Institutes of Health, National Institute of Diabetes and Digestive and Kidney Diseases, Grants DK089066, and by the National Science Foundation, Grant DMS-0701412.

\section{References}

[1] W. M. Deen, C. R. Bridges, B. M. Brenner, and B. D. Myers, "Heteroporous model of glomerular size selectivity: application to normal and nephrotic humans," American Journal of Physiology-Renal Physiology, vol. 249, no. 3, pp. F374-F389, 1985.

[2] J. M. Sands and H. E. Layton, "Urine concentrating mechanism and its regulation," in The Kidney: Physiology and Pathophysiology, D. W. Seldin and G. Giebisch, Eds., pp. 1175-1216, Lippincott Williams \& Wilkins, Philadelphia, Pa, USA, 3d edition, 2000.

[3] H. Ryu and A. T. Layton, "Tubular fluid flow and distal nacl delivery mediated by tubuloglomerular feedback in the rat kidney," Journal of Mathematical Biology. In press.

[4] W. M. Deen, C. R. Robertson, and B. M. Brenner, "A model of glomerular ultrafiltration in the rat," American Journal of Physiology, vol. 223, no. 5, pp. 1178-1183, 1972.

[5] R. L. S. Chang, C. R. Robertson, W. M. Deen, and B. M. Brenner, "Permselectivity of the glomerular capillary wall to macromolecules. I. Theoretical considerations," Biophysical Journal, vol. 15, no. 9, pp. 861-886, 1975.

[6] A. Guasch, W. M. Deen, and B. D. Myers, "Charge selectivity of the glomerular filtration barrier in healthy and nephrotic humans," Journal of Clinical Investigation, vol. 92, no. 5, pp. 2274-2282, 1993.

[7] M. C. Drumond and W. M. Deen, "Structural determinants of glomerular hydraulic permeability," American Journal of Physiology-Renal Physiology, vol. 266, no. 1, pp. F1-F12, 1994.

[8] A. Edwards, B. S. Daniels, and W. M. Deen, "Hindered transport of macromolecules in isolated glomeruli. II. Convection and pressure effects in basement membrane," Biophysical Journal, vol. 72, no. 1, pp. 214-222, 1997.

[9] A. Edwards, B. S. Daniels, and W. M. Deen, "Ultrastructural model for size selectivity in glomerular filtration," American Journal of Physiology—Renal Physiology, vol. 276, no. 6, pp. F892-F902, 1999.

[10] W. M. Deen, M. J. Lazzara, and B. D. Myers, "Structural determinants of glomerular permeability," American Journal of Physiology-Renal Physiology, vol. 281, no. 4, pp. F579-F596, 2001.

[11] A. T. Layton, L. C. Moore, and H. E. Layton, "Multistability in tubuloglomerular feedback and spectral complexity in spontaneously hypertensive rats," American Journal of Physiology_Renal Physiology, vol. 291, no. 1, pp. F79-F97, 2006. 
[12] H. E. Layton, E. B. Pitman, and L. C. Moore, "Bifurcation analysis of TGF-mediated oscillations in SNGFR," American Journal of Physiology—Renal Physiology, vol. 261, no. 5, pp. F904-F919, 1991.

[13] J. Schnermann and J. P. Briggs, "Function of the juxtaglomerular apparatus: control of glomerular hemodynamics and renin secretion," in The Kidney: Physiology and Pathophysiology, D. W. Seldin and G. Giebisch, Eds., pp. 945-980, Lippincott Williams \& Wilkins, Philadelphia, Pa, USA, 3rd edition, 2000.

[14] E. B. Pitman, R. M. Zaritski, K. J. Kesseler, L. C. Moore, and H. E. Layton, "Feedback-mediated dynamics in two coupled nephrons," Bulletin of Mathematical Biology, vol. 66, no. 6, pp. 1463-1492, 2004.

[15] P. P. Leyssac and L. Baumbach, "An oscillating intratubular pressure response to alterations in Henle loop flow in the rat kidney," Acta Physiologica Scandinavica, vol. 117, no. 3, pp. 415-419, 1983.

[16] K. S. Jensen, Nonlinear dynamical phenomena in renal physiology [Ph.D. thesis], The Technical University of Denmark, 1987.

[17] K. S. Jensen, N.-H. Holstein-Rathlou, P. P. Leyssac, E. Mosekilde, and D. R. Rasmussen, "Chaos in a system of interacting nephrons," in Life Sciences: Chaos in Biological Systems, H. Degn, A. V. Holden, and L. F. Olsen, Eds., Plenum Press, New York, NY, USA, 1987.

[18] M. Barfred, E. Mosekilde, and N. H. Holstein-Rathlou, "Bifurcation analysis of nephron pressure and flow regulation," Chaos, vol. 6, no. 3, pp. 280-287, 1996.

[19] J. Schnermann and J. P. Briggs, "Function of the juxtaglomerular apparatus: control of glomerular hemodynamics and renin secretion," in Seldin and Giebisch's the Kidney: Physiology and Pathophysiology, R. J. Alpern and S. C. Hebert, Eds., pp. 589-626, Elsevier/Academic Press , Amsterdam, The Netherlands, 4th edition, 2008.

[20] R. Loutzenhiser, A. Bidani, and L. Chilton, "Renal myogenic response: kinetic attributes and physiological role," Circulation Research, vol. 90, no. 12, pp. 1316-1324, 2002.

[21] H. E. Layton, E. B. Pitman, and L. C. Moore, "Spectral properties of the tubuloglomerular feedback system," American Journal of Physiology-Renal Physiology, vol. 273, no. 4, pp. F635-F649, 1997.

[22] H. E. Layton, E. B. Pitman, and L. C. Moore, "Nonlinear filter properties of the thick ascending limb," American Journal of Physiology—Renal Physiology, vol. 273, no. 4, pp. F625-F634, 1997.

[23] N. H. Holstein-Rathlou and D. J. Marsh, "A dynamic model of the tubuloglomerular feedback mechanism," American Journal of Physiology, vol. 258, no. 5, pp. F1448-F1459, 1990.

[24] T. Sakai, D. A. Craig, A. S. Wexler, and D. J. Marsh, "Fluid waves in renal tubules," Biophysical Journal, vol. 50, no. 5, pp. 805-813, 1986.

[25] D. K. Young and D. J. Marsh, "Pulse wave propagation in rat renal tubules: implications for GFR autoregulation," American Journal of Physiology-Renal Physiology, vol. 9, no. 5, pp. F446-F458, 1981.

[26] C. A. Beuchat, "Structure and concentrating ability of the mammalian kidney: correlations with habitat," American Journal of Physiology-Regulatory, Integrative and Comparative Physiology, vol. 271, no. 1, pp. R157-R179, 1996.

[27] N. H. Holstein-Rathlou and P. P. Leyssac, "Oscillations in the proximal intratubular pressure: a mathematical model," American Journal of Physiology, vol. 252, no. 3, pp. F560F572, 1987.
[28] H. Ryu and A. T. Layton, "Effect of tubular inhomogeneities on feedback-mediated dynamics of a model of a thick ascending limb," Mathematical Medicine and Biology. In press.

[29] J. Chen, I. Sgouralis, L. C. Moore, H. E. Layton, and A. T. Layton, "A mathematical model of the myogenic response to systolic pressure in the afferent arteriole," American Journal of Physiology-Renal Physiology, vol. 300, no. 3, pp. F669-F681, 2011.

[30] I. Sgouralis and A.T. Layton, "Autoregulation and conduction of vasomotor responses in a mathematical model of the rat afferent arteriole," American Journal of Physiology-Renal Physiology, vol. 303, no. 2, pp. 229-239, 2012.

[31] A. T. Layton, H. E. Layton, T. L. Pannabecker, and W. H. Dantzler, "The mammalian urine concentrating mechanism: hypotheses and uncertainties," Physiology, vol. 24, no. 4, pp. 250-256, 2009.

[32] H. E. Layton, E. B. Pitman, and L. C. Moore, "Limit-cycle oscillations and tubuloglomerular feedback regulation of distal sodium delivery," American Journal of PhysiologyRenal Physiology, vol. 278, no. 2, pp. F287-F301, 2000.

[33] A. T. Layton and H. E. Layton, "A semi-lagrangian semiimplicit numerical method for models of the urine concentrating mechanism," SIAM Journal on Scientific Computing, vol. 23, no. 5, pp. 1526-1548, 2002.

[34] A. T. Layton, "Feedback-mediated dynamics in a model of a compliant thick ascending limb," Mathematical Biosciences, vol. 228, no. 2, pp. 185-194, 2010.

[35] D. R. Oldson, H. E. Layton, and L. C. Moore, "Effect of sustained flow perturbations on stability and compensation of tubuloglomerular feedback," American Journal of Physiology-Renal Physiology, vol. 285, no. 5, pp. F972-F989, 2003.

[36] H. E. Layton, E. B. Pitman, and M. A. Knepper, "A dynamic numerical method for models of the urine concentrating mechanism," SIAM Journal on Applied Mathematics, vol. 55, no. 5, pp. 1390-1418, 1995.

[37] A. T. Layton, L. C. Moore, and H. E. Layton, "Tubuloglomerular feedback signal transduction in a compliant thick ascending limb," American Journal of Physiology — Renal Physiology, vol. 302, no. 9, pp. F1188-F1202, 2009.

[38] N. H. Holstein-Rathlou, "Synchronization of proximal intratubular pressure oscillations: evidence for interaction between nephrons," Pflügers Archiv, vol. 408, no. 5, pp. 438443, 1987.

[39] Ö. Källskog and D. J. Marsh, “TGF-initiated vascular interactions between adjacent nephrons in the rat kidney," American Journal of Physiology—Renal Physiology, vol. 259, no. 1, pp. F60-F64, 1990.

[40] K. P. Yip, N. H. Holstein-Rathlou, and D. J. Marsh, "Dynamics of TGF-initiated nephron-nephron interactions in normotensive rats and SHR," American Journal of PhysiologyRenal Physiology, vol. 262, no. 6, pp. F980-F988, 1992.

[41] K. J. Kesseler, Analysis of feedback-mediated oscillations in two coupled nephrons [Ph.D. thesis], Duke University, 2004.

[42] A. T. Layton, L. C. Moore, and H. E. Layton, "Multistable dynamics mediated by tubuloglomerular feedback in a model of coupled nephrons," Bulletin of Mathematical Biology, vol. 71, no. 3, pp. 515-555, 2009.

[43] J. L. Laugesen, E. Mosekilde, and N. H. Holstein-Rathlou, "Synchronization of perioddoubling oscillations in vascular coupled nephrons," Chaos, vol. 21, Article ID 0331128, 12 pages, 2011. 
[44] D. J. Marsh, O. V. Sosnovtseva, E. Mosekilde, and N. H. Holstein-Rathlou, "Vascular coupling induces synchronization, quasiperiodicity, and chaos in a nephron tree," Chaos, vol. 17, no. 1, Article ID 015114, 10 pages, 2007.

[45] A. T. Layton, "A mathematical model of the urine concentrating mechanism in the rat renal medulla. II. Functional implications of three-dimensional architecture," American Journal of Physiology-Renal Physiology, vol. 300, no. 2, pp. F372-F384, 2011.

[46] G. A. Williamson, R. Loutzenhiser, X. Wang, K. Griffin, and A. K. Bidani, "Systolic and mean blood pressures and afferent arteriolar myogenic response dynamics: a modeling approach," American Journal of Physiology-Regulatory, Integrative and Comparative Physiology, vol. 295, no. 5, pp. R1502-R1511, 2008.

[47] D. J. Lush and J. C. S. Fray, "Steady-state autoregulation of renal blood flow: a myogenic model," American Journal of Physiology-Regulatory, Integrative and Comparative Physiology, vol. 247, no. 1, pp. R89-R99, 1984.

[48] B. E. Carlson, J. C. Arciero, and T. W. Secomb, “Theoretical model of blood flow autoregulation: roles of myogenic, shear-dependent, and metabolic responses," American Journal of Physiology-Heart and Circulatory Physiology, vol. 295, no. 4, pp. H1572-H1579, 2008.

[49] J. C. Arciero, B. E. Carlson, and T. W. Secomb, "Theoretical model of metabolic blood flow regulation: roles of ATP release by red blood cells and conducted responses," American Journal of Physiology-Heart and Circulatory Physiology, vol. 295, no. 4, pp. H1562-H1571, 2008.

[50] J. M. Gonzalez-Fernandez and B. Ermentrout, "On the origin and dynamics of the vasomotion of small arteries," Mathematical Biosciences, vol. 119, no. 2, pp. 127-167, 1994.

[51] M. Steinhausen, K. Endlich, R. Nobiling, N. Parekh, and F. Schütt, "Electrically induced vasomotor responses and their propagation in rat renal vessels in vivo," Journal of Physiology, vol. 505, no. 2, pp. 493-501, 1997.

[52] D. J. Marsh, O. V. Sosnovtseva, K. H. Chon, and N. H. Holstein-Rathlou, "Nonlinear interactions in renal blood flow regulation," American Journal of Physiology-Regulatory Integrative and Comparative Physiology, vol. 288, no. 5, pp. R1143-R1159, 2005.

[53] W. Kuhn and K. Ryffel, "Herstellung konzentrierter Loüungen aus verdünnten durch blosse Membranwirkung: ein Modellversuch zur Funktion der Niere," Zeitschrift Fuer Physikalische Chemie, vol. 276, pp. 145-178, 1942.

[54] J. M. Sands and H. E. Layton, "The urine concentrating mechanism and urea transporters," in Seldin and GiebiSch's the Kidney: Physiology and Pathophysiology, R. J. Alpern and S. C. Hebert, Eds., pp. 1143-11178, Elsevier, New York, NY, USA, 4th edition, 2008.

[55] W. H. Dantzler, T. L. Pannabecker, A. T. Layton, and H. E. Layton, "Urine concentrating mechanism in the inner medulla of the mammalian kidney: role of three-dimensional architecture," Acta Physiologica, vol. 202, no. 3, pp. 361-378, 2011.

[56] F. C. Hoppensteadt and C.S. Peskin, Mathematics in Medicine and the Life Sciences, Springer, New York, NY, USA, 2nd edition, 2001.

[57] J. L. Stephenson, "Concentration of urine in a central core model of the renal counterflow system," Kidney International, vol. 2, pp. 85-94, 1972.

[58] A. T. Layton, T. L. Pannabecker, W. H. Dantzler, and H. E. Layton, "Two modes for concentrating urine in rat inner medulla," American Journal of Physiology-Renal Physiology, vol. 287, no. 4, pp. F816-F839, 2004.

[59] A. T. Layton, T. L. Pannabecker, W. H. Dantzler, and H. E. Layton, "Functional implications of the three-dimensional architecture of the rat renal inner medulla," American Journal of Physiology —Renal Physiology, vol. 298, no. 4, pp. F973F987, 2010.

[60] A. T. Layton, T. L. Pannabecker, W. H. Dantzler, and H. E. Layton, "Hyperfiltration and inner stripe hypertrophy may explain findings by Gamble and coworkers," American Journal of Physiology—Renal Physiology, vol. 298, no. 4, pp. F962F972, 2010.

[61] H. E. Layton, "Concentrating urine in the inner medulla of the kidney," Comments on Theoretical Biology, vol. 1, pp. 179196, 1989.

[62] H. E. Layton, M. A. Knepper, and C. L. Chou, "Permeability criteria for effective function of passive countercurrent multiplier," American Journal of Physiology-Renal Physiology, vol. 270, no. 1, pp. F9-F20, 1996.

[63] J. L. Stephenson, "Concentrating engines and the kidney. I. Central core model of the renal medulla," Biophysical Journal, vol. 13 , no. 6, pp. 512-545, 1973.

[64] J. L. Stephenson, "Concentrating engines and the kidney. II. Multisolute central core systems," Biophysical Journal, vol. 13, no. 6, pp. 546-567, 1973.

[65] J. L. Stephenson, "Concentrating engines and the kidney. III. Canonical mass balance equation for multinephron models of the renal medulla," Biophysical Journal, vol. 16, no. 11, pp. 1273-1286, 1976.

[66] J. L. Stephenson, "Concentrating engines and the kidney. IV. Mass balance in a single stage of a multistage model of the renal medulla," Mathematical Biosciences, vol. 55, no. 3-4, pp. 265-278, 1981.

[67] J. L. Stephenson, Y. Zhang, and R. Tewarson, "Electrolyte, urea, and water transport in a two-nephron central core model of the renal medulla," American Journal of Physiology-Renal Physiology, vol. 257, no. 3, pp. F399-F413, 1989.

[68] H. E. Layton, J. M. Davies, G. Casotti, and E. J. Braun, "Mathematical model of an avian urine concentrating mechanism," American Journal of Physiology — Renal Physiology, vol. 279, no. 6, pp. F1139-F1160, 2000.

[69] M. Marcano-Velázquez and H. E. Layton, "An inverse algorithm for a mathematical model of an avian urine concentrating mechanism," Bulletin of Mathematical Biology, vol. 65, no. 4, pp. 665-691, 2003.

[70] M. Marcano, A. T. Layton, and H. E. Layton, "An optimization algorithm for a distributed-loop model of an avian urine concentrating mechanism," Bulletin of Mathematical Biology, vol. 68, no. 7, pp. 1625-1660, 2006.

[71] F. M. A. McNabb, "A comparative study of water balance in three species of quail-II. Utilization of saline drinking solutions," Comparative Biochemistry and Physiology, vol. 28, no. 3, pp. 1059-1074, 1969.

[72] M. Imai and J. P. Kokko, "Sodium chloride, urea, and water transport in the thin ascending limb of Henle: generation of osmotic gradients by passive diffusion of solutes," Journal of Clinical Investigation, vol. 53, no. 2, pp. 393-402, 1974.

[73] M. Imai and E. Kusano, "Effects of arginine vasopressin on the thin ascending limb of Henle's loop of hamsters," American Journal of Physiology — Renal Physiology, vol. 12, no. 2, pp. F167-F172, 1982. 
[74] D. J. Marsh and S. P. Azen, "Mechanism of $\mathrm{NaCl}$ reabsorption by hamster thin ascending limbs of Henle's loop," American Journal of Physiology, vol. 228, no. 1, pp. 71-79, 1975.

[75] D. J. Marsh and S. Solomon, "Analysis of electrolyte movement in thin Henle's loops of hamster papilla," American journal of physiology, vol. 208, pp. 1119-1128, 1965.

[76] J. P. Kokko and F. C. Rector, "Countercurrent multiplication system without active transport in inner medulla," Kidney International, vol. 2, no. 4, pp. 214-223, 1972.

[77] H. E. Layton, "Mathematical models of the mammalian urine concentrating mechanism," in Membrane Transport and Renal Physiology, H. E. Layton and A. M. Weinstein, Eds., vol. 129 of The IMA Volumes in Mathematics and Its Applications, pp. 233-272, Springer, New York, NY, USA, 2002.

[78] S. R. Thomas, "Cycles and separations in a model of the renal medulla," American Journal of Physiology-Renal Physiology, vol. 275, no. 5, pp. F671-F690, 1998.

[79] S. R. Thomas and A. S. Wexler, "Inner medullary external osmotic driving force in a 3-D model of the renal concentrating mechanism," American Journal of Physiology-Renal Physiology, vol. 269, no. 2, pp. F159-F171, 1995.

[80] A. S. Wexler, R. E. Kalaba, and D. J. Marsh, "Threedimensional anatomy and renal concentrating mechanism. I. Modeling results," American Journal of Physiology-Renal Physiology, vol. 260, no. 3, pp. F368-F383, 1991.

[81] W. Kriz, "Structural organization of the renal medulla: comparative and functional aspects," American Journal of Physiology-Regulatory Integrative and Comparative Physiology, vol. 241, no. 1, pp. R3-R16, 1981.

[82] W. Kriz, "Der architektonische und funktioneile Aufbau der Rattenniere," Zeitschrift für Zellforschung und Mikroskopische Anatomie, vol. 82, no. 4, pp. 495-535, 1967.

[83] W. Kriz and H. Koepsell, "The structural organization of the mouse kidney," Zeitschrift für Anatomie und Entwicklungsgeschichte, vol. 144, no. 2, pp. 137-163, 1974.

[84] W. Kriz, J. Schnermann, and H. Koepsell, "The position of short and long loops of Henle in the rat kidney," Zeitschrift für Anatomie und Entwicklungsgeschichte, vol. 138, no. 3, pp. 301-319, 1972.

[85] T. L. Pannabecker, D. E. Abbott, and W. H. Dantzler, "Threedimensional functional reconstruction of inner medullary thin limbs of Henle's loop," American Journal of PhysiologyRenal Physiology, vol. 286, no. 1, pp. F38-F45, 2004.

[86] T. L. Pannabecker and W. H. Dantzler, "Three-dimensional lateral and vertical relationships of inner medullary loops of Henle and collecting ducts," American Journal of PhysiologyRenal Physiology, vol. 287, no. 4, pp. F767-F774, 2004.

[87] T. L. Pannabecker and W. H. Dantzler, "Three-dimensional architecture of inner medullary vasa recta," American Journal of Physiology-Renal Physiology, vol. 290, no. 6, pp. F1355F1366, 2006.

[88] L. Bankir and C. de Rouffignac, "Urinary concentrating ability: insights from comparative anatomy," American Journal of Physiology-Regulatory, Integrative and Comparative Physiology, vol. 249, no. 6, pp. R643-R666, 1985.

[89] L. Bankir, N. Bouby, and M. M. Trinh-Trang-Tan, "Heterogeneity of nephron anatomy," Kidney International, vol. 31, supplement 20, pp. S25-S39, 1987.

[90] M. A. Knepper and F. Roch-Ramel, "Pathways of urea transport in the mammalian kidney," Kidney International, vol. 31, no. 2, pp. 629-633, 1987.
[91] W. Kriz and A. F. Lever, "Renal countercurrent mechanisms: structure and function," American Heart Journal, vol. 78, no. 1, pp. 101-118, 1969.

[92] W. Kriz and B. Kaissling, "Structural organization of the mammalian kidney," in The Kidney: Physiology and Pathophysiology, pp. 587-654, Lippincott Williams \& Wilkins, Philadelphia, Pa, USA, 3rd edition, 2000.

[93] K. V. Lemley and W. Kriz, "Cycles and separations: the histotopography of the urinary concentrating process," Kidney International, vol. 31, no. 2, pp. 538-548, 1987.

[94] M. A. Knepper, G. M. Saidel, and P. J. Palatt, "Mathematical model of renal regulation of urea excretion," Medical and Biological Engineering and Computing, vol. 14, no. 4, pp. 408426, 1976.

[95] P. S. Chandhoke and G. M. Saidel, "Mathematical model of mass transport throughout the kidney: effects of nephron heterogeneity and tubular-vascular organization," Annals of Biomedical Engineering, vol. 9, no. 4, pp. 263-301, 1981.

[96] A. S. Wexler, R. E. Kalaba, and D. J. Marsh, "Threedimensional anatomy and renal concentrating mechanism. II. Sensitivity results," American Journal of Physiology — Renal Physiology, vol. 260, no. 3, pp. F384-F394, 1991.

[97] X. Wang, S. R. Thomas, and A. S. Wexler, "Outer medullary anatomy and the urine concentrating mechanism," American Journal of Physiology_Renal Physiology, vol. 274, no. 2, pp. F413-F424, 1998.

[98] A. T. Layton and H. E. Layton, "A region-based mathematical model of the urine concentrating mechanism in the rat outer medulla. I. Formulation and base-case results," American Journal of Physiology—Renal Physiology, vol. 289, no. 6, pp. F1346-F1366, 2005.

[99] A. T. Layton and H. E. Layton, "A region-based mathematical model of the urine concentrating mechanism in the rat outer medulla. II. Parameter sensitivity and tubular inhomogeneity," American Journal of Physiology—Renal Physiology, vol. 289, no. 6, pp. F1367-F1381, 2005.

[100] A. T. Layton and H. E. Layton, "Countercurrent multiplication may not explain the axial osmolality gradient in the outer medulla of the rat kidney," American Journal of Physiology-Renal Physiology, vol. 301, no. 5, pp. F1047F1056, 2011.

[101] A. T. Layton, "A mathematical model of the urine concentrating mechanism in the rat renal medulla. I. Formulation and base-case results," American Journal of Physiology — Renal Physiology, vol. 300, no. 2, pp. F356-F371, 2011.

[102] A. T. Layton, W. H. Dantzler, and T. L. Pannabecker, "Urine concentrating mechanism: impact of vascular and tubular architecture and a proposed descending limb urea$\mathrm{Na}^{+}$cotransporter," American Journal of Physiology-Renal Physiology, vol. 302, no. 5, pp. F591-F605, 2012.

[103] T. L. Pannabecker, C. S. Henderson, and W. H. Dantzler, "Quantitative analysis of functional reconstructions reveals lateral and axial zonation in the renal inner medulla," American Journal of Physiology-Renal Physiology, vol. 294, no. 6, pp. F1306-F1314, 2008.

[104] W. Neuhofer and F. X. Beck, "Cell survival in the hostile environment of the renal medulla," Annual Review of Physiology, vol. 67, pp. 531-555, 2005.

[105] A. W. Cowley, D. L. Mattson, S. Lu, and R. J. Roman, "The renal medulla and hypertension," Hypertension, vol. 25, no. 4, pp. 663-673, 1995.

[106] R. G. Evans, B. S. Gardiner, D. W. Smith, and P. M. O'Connor, "Intrarenal oxygenation: unique challenges and the biophysical basis of homeostasis," American Journal of 
Physiology—Renal Physiology, vol. 295, no. 5, pp. F1259F1270, 2008.

[107] B. S. Gardiner, D. W. Smith, P. M. O'Connor, and R. G. Evans, "A mathematical model of diffusional shunting of oxygen from arteries to veins in the kidney," American Journal of Physiology-Renal Physiology, vol. 300, no. 6, pp. F1339F1352, 2011.

[108] W. Zhang and A. Edwards, "Oxygen transport across vasa recta in the renal medulla," American Journal of PhysiologyHeart and Circulatory Physiology, vol. 283, no. 3, pp. H1042H1055, 2002.

[109] J. Chen, A. T. Layton, and A. Edwards, "A mathematical model of $\mathrm{O}_{2}$ transport in the rat outer medulla. I. Model formulation and baseline results," American Journal of Physiology_Renal Physiology, vol. 297, no. 2, pp. F517-F536, 2009.

[110] J. Chen, A. Edwards, and A. T. Layton, "A mathematical model of $\mathrm{O}_{2}$ transport in the rat outer medulla. II. Impact of outer medullary architecture," American Journal of Physiology_Renal Physiology, vol. 297, no. 2, pp. F537-F548, 2009.

[111] J. Chen, A. Edwards, and A. T. Layton, "Effects of pH and medullary blood flow on oxygen transport and sodium reabsorption in the rat outer medulla," American Journal of Physiology_Renal Physiology, vol. 298, no. 6, pp. F1369F1383, 2010.

[112] A. Edwards and A. T. Layton, "Nitric oxide and superoxide transport in a cross section of the rat outer medulla. I. Effects of low medullary oxygen tension," American Journal of Physiology-Renal Physiology, vol. 299, no. 3, pp. F616-F633, 2010.

[113] A. Edwards and A. T. Layton, "Nitric oxide and superoxide transport in a cross section of the rat outer medulla. II. Reciprocal interactions and tubulovascular cross talk," American Journal of Physiology — Renal Physiology, vol. 299, no. 3, pp. F634-F647, 2010.

[114] A. M. Weinstein, "Mathematical models of renal fluid and electrolyte transport: acknowledging our uncertainty," American Journal of Physiology-Renal Physiology, vol. 284, no. 5, pp. F871-F884, 2003. 


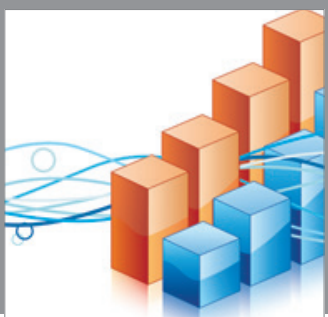

Advances in

Operations Research

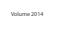

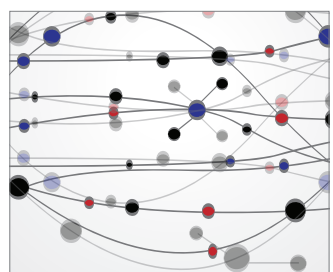

\section{The Scientific} World Journal
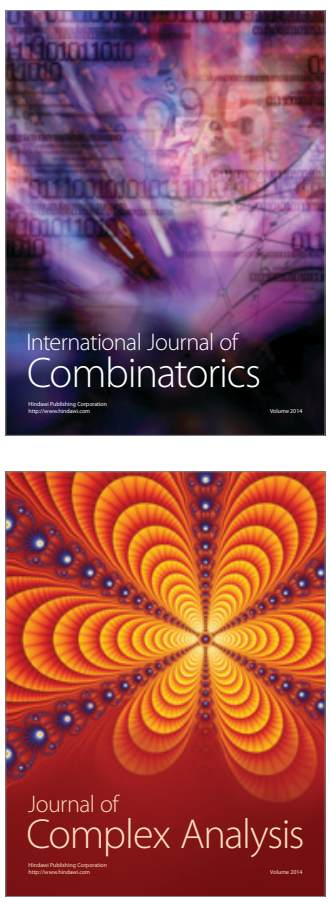

International Journal of

Mathematics and

Mathematical

Sciences
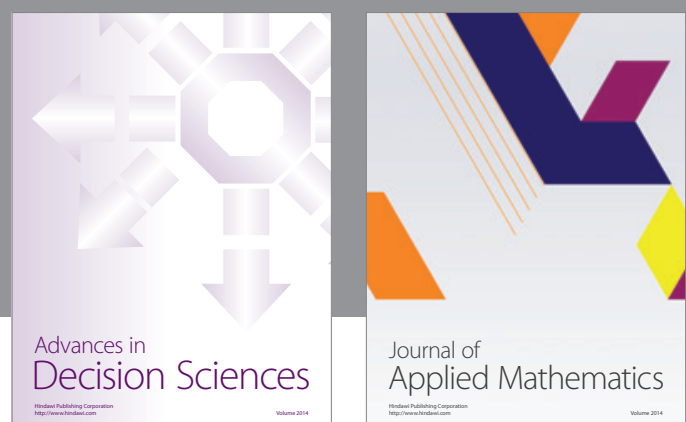

Journal of

Applied Mathematics
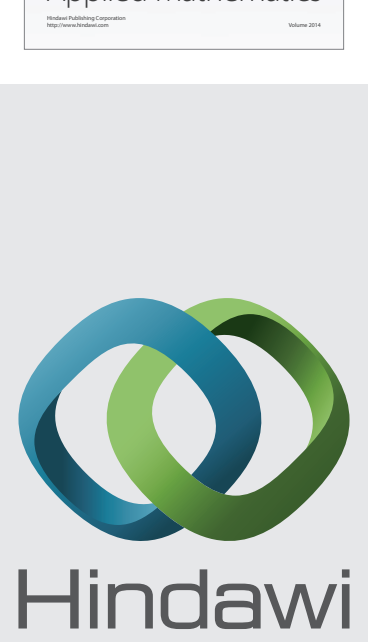

Submit your manuscripts at http://www.hindawi.com
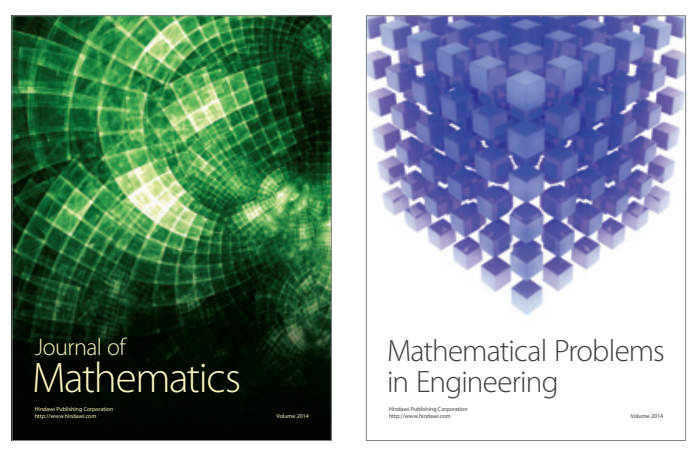

Mathematical Problems in Engineering
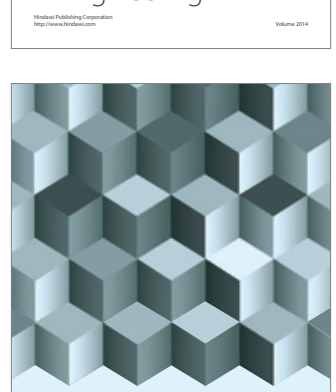

Journal of

Function Spaces
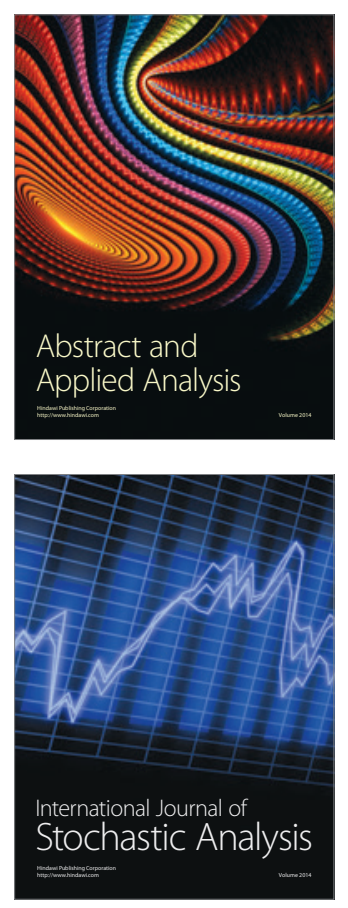

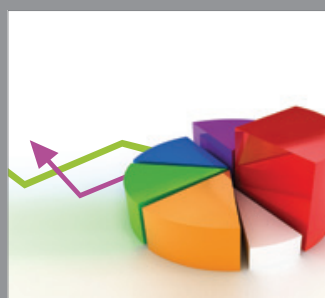

ournal of

Probability and Statistics

Promensencen
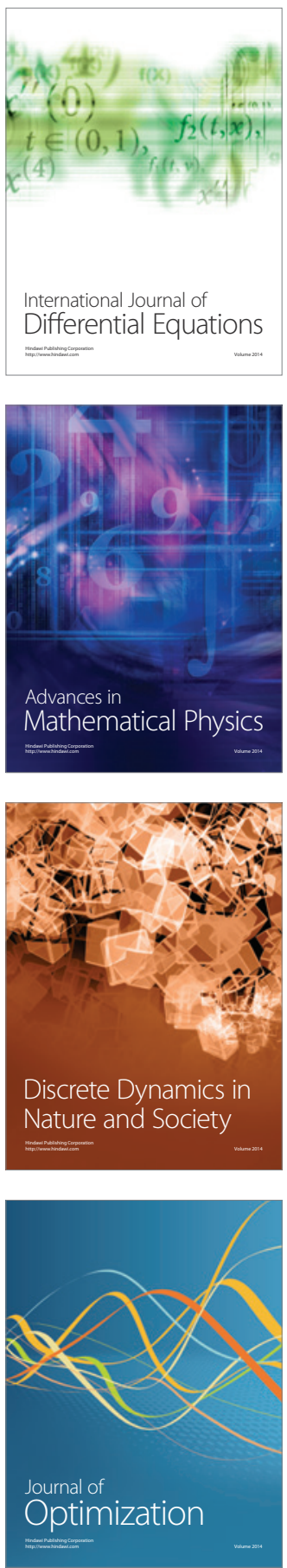